\title{
Drug-Drug Interactions with Antiretroviral Drugs in Pregnant Women Living with HIV: Are They Different from Non-Pregnant Individuals?
}

\author{
Vera E. Bukkems ${ }^{1} \cdot$ Angela Colbers $^{1}$ (1) $\cdot$ Catia Marzolini $^{2,3} \cdot$ Jose Molto $^{4,5,6} \cdot$ David M. Burger $^{1}$
}

Published online: 22 July 2020

(c) The Author(s) 2020

\begin{abstract}
Background and Objective Although the separate effects of drug-drug interactions and pregnancy on antiretroviral drug pharmacokinetics have been widely studied and described, their combined effect is largely unknown. Physiological changes during pregnancy may change the extent or clinical relevance of a drug-drug interaction in a pregnant woman. This review aims to provide a detailed overview of the mechanisms, magnitude, and clinical significance of antiretroviral drug-drug interactions in pregnant women.

Methods We performed a literature search and selected studies that compared the magnitude of drug-drug interactions with antiretroviral drugs in pregnant vs non-pregnant women.

Results Forty-eight papers examining drug-drug interactions during pregnancy were selected, of which the majority focused on pharmacokinetic boosting. Other selected studies examined the drug-drug interactions between efavirenz and lumefantrine, efavirenz and tuberculosis drugs, etravirine and tenofovir disoproxil fumarate, atazanavir and tenofovir disoproxil, and mefloquine and nevirapine in pregnant compared to non-pregnant women. The clinical significance of antiretroviral drug-drug interactions changed during pregnancy from a minimal effect to a contra-indication. In almost all cases, the clinical significance of a drug-drug interaction was more relevant in pregnant women, owing to the combined effects of pregnancyinduced physiological changes and drug-drug interactions leading to a lower absolute drug exposure.

Conclusions Multiple studies show that the clinical relevance of a drug-drug interaction can change during pregnancy. Unfortunately, many potential interactions have not been studied in pregnancy, which may place pregnant women living with human immunodeficiency virus and their newborns at risk.
\end{abstract}

Angela Colbers

Angela.Colbers@radboudumc.nl

1 Department of Pharmacy, Radboud University Medical Center and Radboud Institute for Health Sciences (RIHS), Geert Grooteplein Zuid 10, 6525 GA Nijmegen, the Netherlands

2 Division of Infectious Diseases and Hospital Epidemiology, Departments of Medicine and Clinical Research, University Hospital of Basel and University of Basel, Basel, Switzerland

3 Department of Molecular and Clinical Pharmacology, University of Liverpool, Liverpool, UK

4 Fundació Lluita Contra La Sida, Badalona, Spain

5 Infectious Diseases Department, Hospital Universitari Germans Trias I Pujol, Badalona, Spain

6 Universitat Autònoma de Barcelona (UAB), Barcelona, Spain

\section{Key Points}

More attention is needed from both researchers and clinicians to demonstrate which drug-drug interactions (DDIs) are clinically relevant in special populations.

The extent of a DDI may differ if the exposure of the perpetrator changes during pregnancy. DDIs at the level of intestinal transporters do not seem to be different in pregnant women.

The clinical significance of most DDIs in this review changed during pregnancy when looking at the absolute drug exposure in pregnant women. The combined effects of the DDI and other pregnancy-related physiological changes may lead to a more pronounced reduction in drug exposure, thereby exposing to the risk of therapeutic failure. 


\section{Introduction}

All patients living with human immunodeficiency virus (HIV) must be exposed to an adequate concentration of antiretroviral drugs (ARVs) to achieve and maintain virologic suppression. In pregnancy, the exposure, and thus the efficacy of ARVs, can be modified by several factors such as drug-drug interactions (DDIs) and pregnancy-induced physiological changes. These factors have to be taken into consideration when selecting an individual ARV regimen in addition to side effects, resistance testing, previous antiviral regimens, and practical aspects [1].

Several studies have demonstrated the clinically relevant effect of DDIs on the pharmacokinetics of ARVs. Protease inhibitors (PIs), non-nucleoside reverse transcriptase inhibitors, and the integrase strand inhibitor (INSTI) elvitegravir (EVG) are extensively metabolized by the cytochrome P450 enzyme (CYP450) system leading to a variety of relevant DDIs $[2,3]$. For example, the exposure of multiple ARVs is decreased as a result of CYP induction by rifampicin [4]. However, ARVs can also influence other co-medications: efavirenz (EFV) induces CYP3A4 activity and can, thereby, decrease the efficacy of several co-medications [5]. We also make use of interactive effects, for example CYP3A4 inhibition by ritonavir or cobicistat to increase the exposure to PIs and EVG (pharmacokinetic boosting) [6]. Drug-drug interactions are not limited to CYP interactions, but extend to non-CYP metabolism, drug transporters, and the absorption, distribution, and elimination of drugs. Inhibition of efflux transporter proteins in the gastrointestinal tract by cobicistat can increase the absorption of substrates of this transporter [7]. Drug absorption can also be affected by chelation with another drug and by $\mathrm{pH}$-influencing drugs $[8,9]$. Plasma protein displacement can affect the total plasma concentration and distribution of some highly protein-bound drugs [10].

It is also clearly demonstrated that physiological changes in pregnancy influence the pharmacokinetics of ARVs and co-medications [11]. Drug absorption may be altered because of increased gastric $\mathrm{pH}$ and slower intestinal motility $[12,13]$. Physiological processes affect the ARV distribution and changes in plasma protein concentrations can affect the unbound ARV fraction of highly protein-bound drugs [14]. Finally, changes in hepatic blood flow, metabolic enzyme activity, glomerular filtration rate, and renal blood flow may alter the metabolism and elimination of ARVs and co-medication $[14,15]$.

In general, dosing recommendations and contra-indications of ARVs are based on DDI studies in healthy volunteers or individuals living with HIV, while pregnant women are excluded. However, pregnancy-related physiological changes may influence the magnitude or clinical relevance of a DDI. A non-clinically relevant DDI leading to a marginally lower exposure of the ARV in a non-pregnant woman may become relevant when adding the effect of pregnancy causing a potential risk for virologic failure and motherto-child transmission. As an example, labels were recently updated to discourage the use of cobicistat-boosted regimens during pregnancy owing to a reduced exposure of cobicistat leading to insufficient concentrations of the boosted ARV during pregnancy, whereas this effect is not observed in nonpregnant women [16].

Antiretroviral drug exposure is difficult to predict in pregnant women, especially when the women are receiving interacting co-medications. The ARV exposure is determined by the different pharmacokinetic processes in the body. A pharmacokinetic process, for example hepatic metabolism by CYP3A4 enzymes, can be influenced by a DDI and physiological pregnancy changes concurrently. Pregnancy hormones induce CYP3A4 activity, while an interacting drug can inhibit CYP3A4 activity [14]. This is further complicated if the DDI degree is concentration dependent because the concentration of the interacting drug can be impacted by the DDI itself and by the physiological changes related to pregnancy. These interrelated effects make it difficult to predict the magnitude of DDIs in pregnant women, and studies examining DDIs in pregnant women are, therefore, necessary to ensure adequate ARV exposure and efficacy. This article provides an overview of the current knowledge on DDIs with ARVs in pregnant women living with HIV. The inter-related effects of DDIs and physiological changes in pregnancy are further elucidated in the results section with the examples from the literature. We discuss the mechanisms leading to altered ARV exposure and the effect in terms of clinical relevance.

\section{Search Methodology}

PubMed and Embase searches were performed to find the relevant articles about DDIs in pregnant women living with HIV. The following terms were used: (Pregnancy OR pregnant) AND drug interaction* AND anti human immunodeficiency virus agents. As boosting is not always referred to as being an interaction, a second search term was used: 'Pharmacokinetic*' AND 'HIV' AND 'pregnant OR pregnancy' AND 'ritonavir OR cobicistat'. In addition, registration information from the European Medicines Agency and the US Food and Drug Administration was used and abstracts of relevant international conferences (Conference on Retroviruses and Opportunistic Infections, International Workshop on Clinical Pharmacology of Antiviral Therapy, European AIDS Conference and International AIDS Conference) were screened.

We selected studies comparing drug exposure in pregnant women with exposure in women postpartum or non-pregnant women. Drug-drug interactions in pregnant women 
are discussed for enzyme inhibition, enzyme induction, transporter inhibition, and for other unknown mechanisms. For every interaction mechanism, three scenarios are discussed: (1) the effect of DDIs in non-pregnant individuals (mostly studied in men); (2) the effect of pregnancy on drug exposure in the absence of an interacting drug; and (3) the combined effect of DDIs and pregnancy on drug exposure in pregnant women. In addition, changes in the DDI magnitude and the related clinical significance in pregnant women are discussed.

\section{Studied Interactions in Pregnant Women Living with HIV}

In total, 48 relevant papers and abstracts were selected. The majority of these studies examined the DDI between a booster and PIs or EVG in pregnant compared to postpartum women. Other selected studies examined the DDI between EFV and lumefantrine (LF) $[n=1]$, EFV and tuberculosis drugs $(n=1)$, etravirine (ETR) and tenofovir disoproxil fumarate (TDF) $[n=1]$, tenofovir alafenamide (TAF) and cobicistat $(n=2)$, atazanavir (ATV) and TDF $(n=3)$, and mefloquine and nevirapine $[n=1]$ in pregnant compared to non-pregnant women.

\subsection{Enzyme Inhibition}

\subsubsection{Boosters and Protease Inhibitors/Elvitegravir}

The DDI between boosters (i.e., cobicistat and ritonavir) and PIs/EVG has been extensively studied in pregnant women living with HIV. The effect of pregnancy-related physiological changes on the DDI was evaluated by comparing the PI/EVG exposure during pregnancy and postpartum in the same women. A decreased PI/EVG exposure was repeatedly confirmed in pregnant women during the first, second, and third trimester compared to postpartum. The average area under the curve (AUC) decrease had a range of $5-56 \%$ for PIs and $7-44 \%$ for EVG (Table 1) [17-53].

Figure 1 discusses the mechanism of this DDI in pregnant women considering three scenarios, which all compare to non-pregnant women using PIs or EVG without boosters. Figure 1a depicts the DDI in the non-pregnant situation where the PI/EVG exposure is greatly increased owing to CYP3A4 inhibition by the booster [54-56]. Figure $1 \mathrm{~b}$ shows the probable effect of pregnancy on PI/EVG and booster exposures in the absence of the DDI. Hormonal changes in pregnancy induce CYP3A4 activity, which results, likely in combination with other physiological pregnancy changes, in decreased PI/EVG and booster exposures [14]. Pharmacokinetic assessments of unboosted indinavir, a PI primarily metabolized by CYP3A4, have been performed in pregnant women living with HIV, mimicking the situation in Fig. 1b. These studies showed a $62-86 \%$ decrease in indinavir AUC $0-8 \mathrm{~h}$ during pregnancy compared with postpartum [57-59]. In one study, the decreased indinavir exposure corresponded to an increase in the urinary metabolic ratio of cortisol, a reliable marker for CYP3A4 activity, supporting that induced CYP3A4 activity contributed to decreased PI/EVG exposure during pregnancy [59]. Another study reported the metabolic ratio of cortisol to be $35 \%(1-81 \%)$ [median (95\% confidence interval $[\mathrm{CI}])]$ higher during the third trimester of pregnancy compared to postpartum [60].

As described in Fig. 1c and Table 1, the combined effects (pregnant women taking a boosted PI/EVG regimen) lead to lower PI/EVG exposures than non-pregnant women taking a boosted PI/EVG regimen. The median (range) boosted indinavir $\mathrm{AUC}_{0-12 \mathrm{~h}}$ was 27.1 (18.6-44.7) $\mu \mathrm{g} * \mathrm{~h} / \mathrm{mL}$ during postpartum compared with $16.1(7.5-39.9) \mu \mathrm{g}^{*} \mathrm{~h} / \mathrm{mL}$ in the third trimester, showing a $40 \%$ decrease for ritonavir-boosted indinavir during pregnancy (Table 1) [41]. The ritonavir $\mathrm{AUC}_{0-12 \mathrm{~h}}$ was also decreased by $60 \%$ during pregnancy, as a result of both pregnancy-related CYP induction and of other physiological changes (i.e., decreased plasma albumin) [Fig. 1c, Table 1] [41, 46]. The comparison of unboosted and boosted indinavir pharmacokinetics shows that pregnancy has a smaller impact on ritonavir-boosted indinavir ( 40\%) than unboosted indinavir (62-86\%) and that the absolute indinavir exposure is higher for ritonavir-boosted indinavir than for unboosted indinavir in pregnant women [41, 57-59]. This suggests that CYP3A4 inhibition by ritonavir, despite a reduction in ritonavir exposure during pregnancy, compensates, to some extent, the CYP3A4 induction in pregnancy (Fig. 1c).

Physiological changes in pregnancy seem to have a different effect on ritonavir- and cobicistat-boosted regimens, as shown in Table 1. The darunavir (DRV) trough concentration $\left(C_{\text {trough }}\right)$ seems to be particularly lower during pregnancy in cobicistat- compared to ritonavir-boosted DRV $800 \mathrm{mg}$ once-daily regimens; boosting with cobicistat resulted in a $71-92 \%$ decrease in $C_{\text {trough }}$ vs $24-64 \%$ with ritonavir boosting $[25,26,28-31,33,34]$. Similarly, the ATV $C_{\text {trough }}$ is lower in cobicistat- compared to ritonavir-boosted regimens, and EVG $C_{\text {trough }}$ is also excessively decreased during pregnancy on average by $81-89 \%$ [17-24, 35-38]. Because of the pronounced reduction in $C_{\text {trough, }}$ which is considered to be mostly related to efficacy, cobicistat-boosted regimens are no longer recommended during pregnancy [16]. The difference in booster efficacy in pregnant women can be caused by multiple processes.

First, the decrease in cobicistat AUC and especially the $C_{\text {trough }}$ seems larger compared to the decrease in ritonavir AUC and $C_{\text {trough }}$ (Table 1). Cobicistat concentrations in pregnant women largely drop below the half maximal inhibitory concentration for CYP3A4 inhibition (i.e., $0.11 \mathrm{mg} / \mathrm{L}$ ) to 


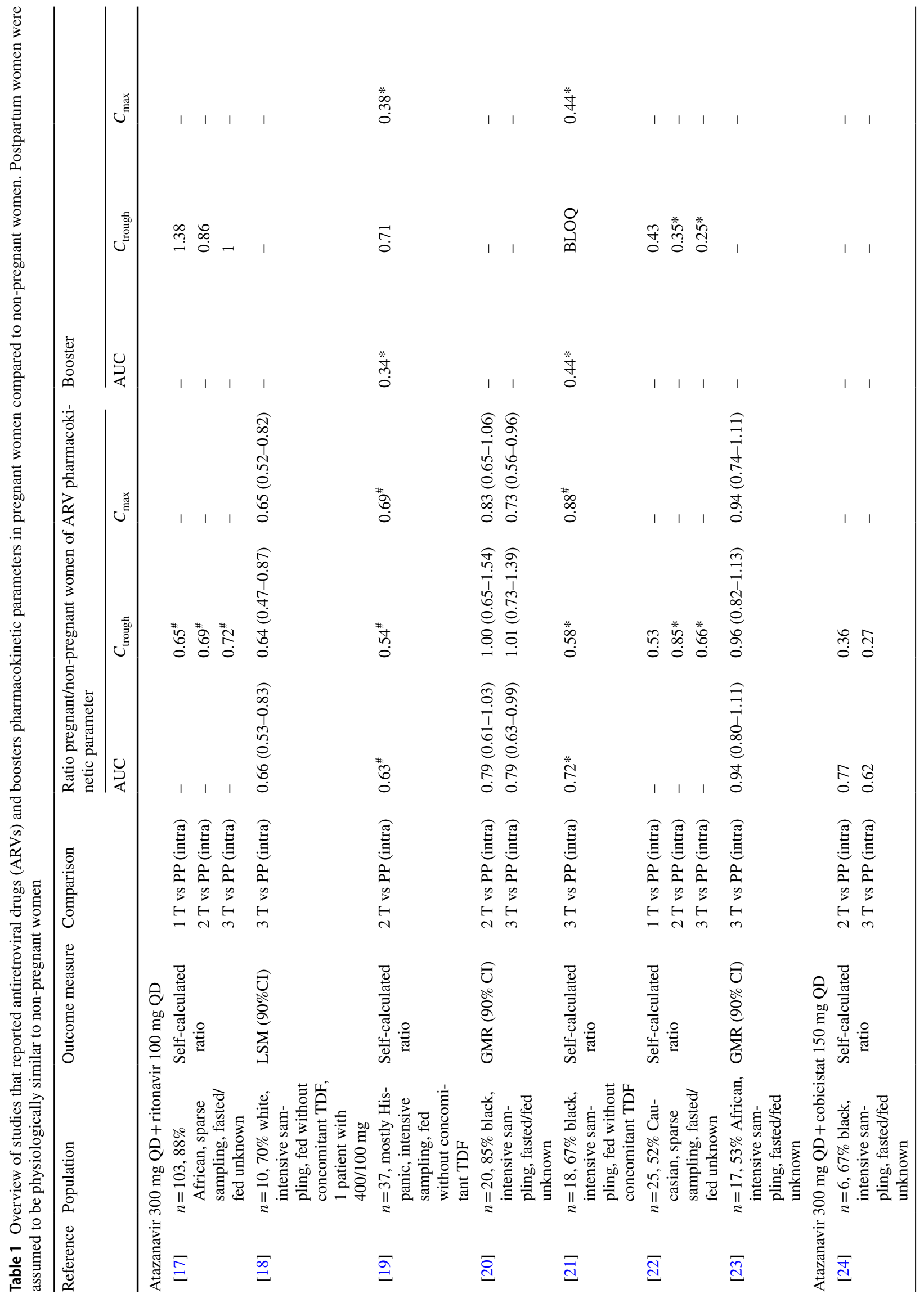




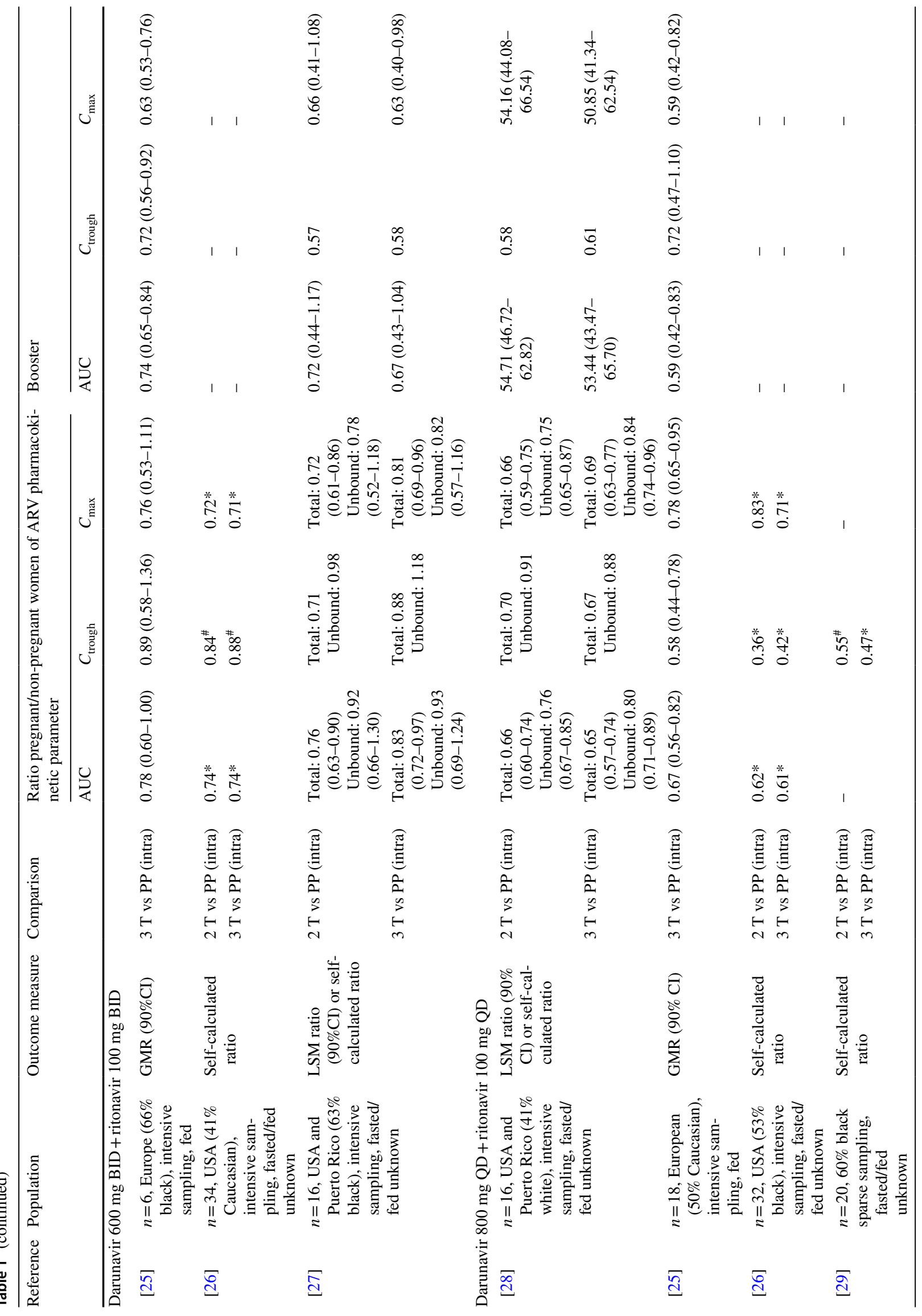




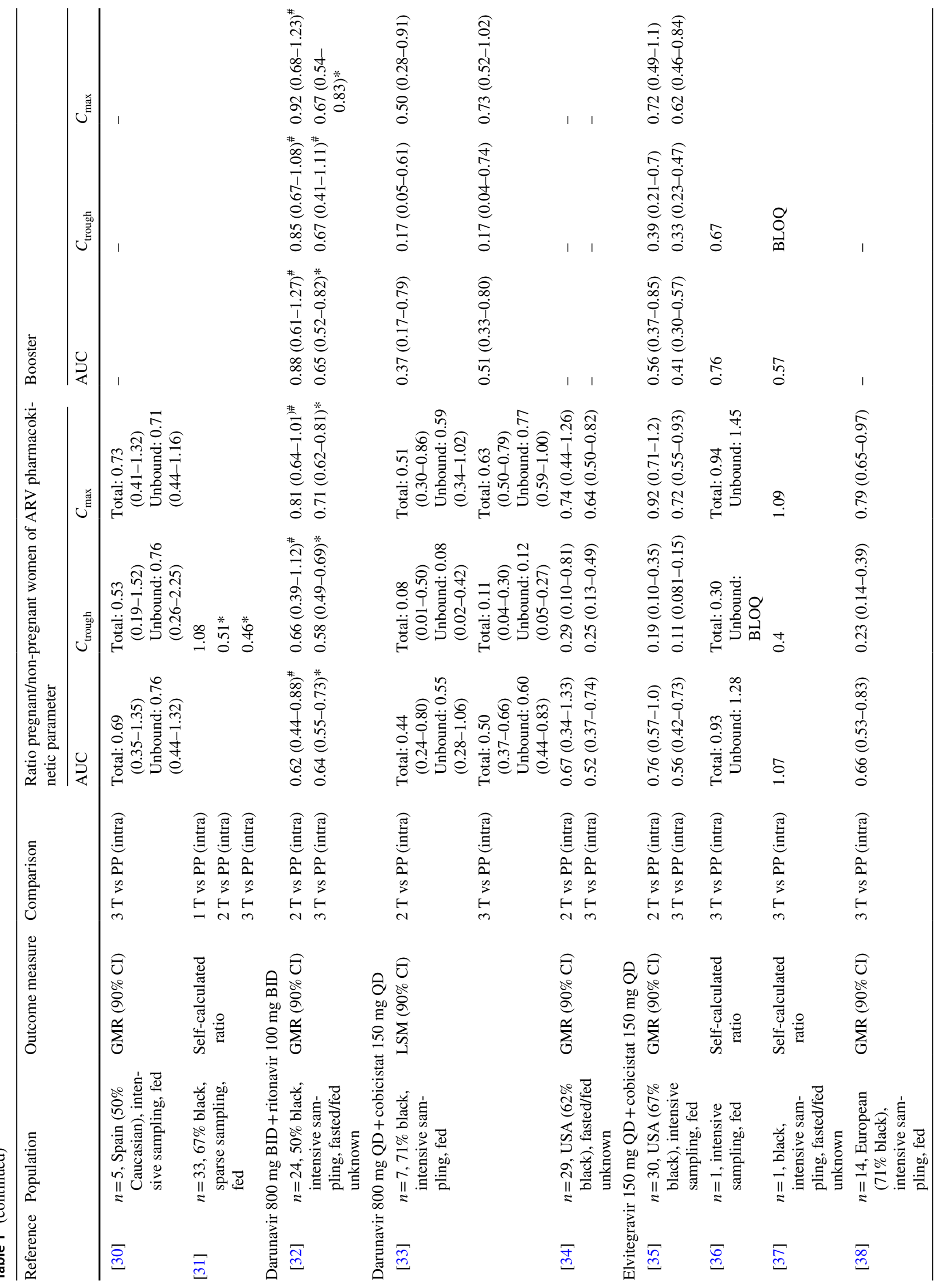




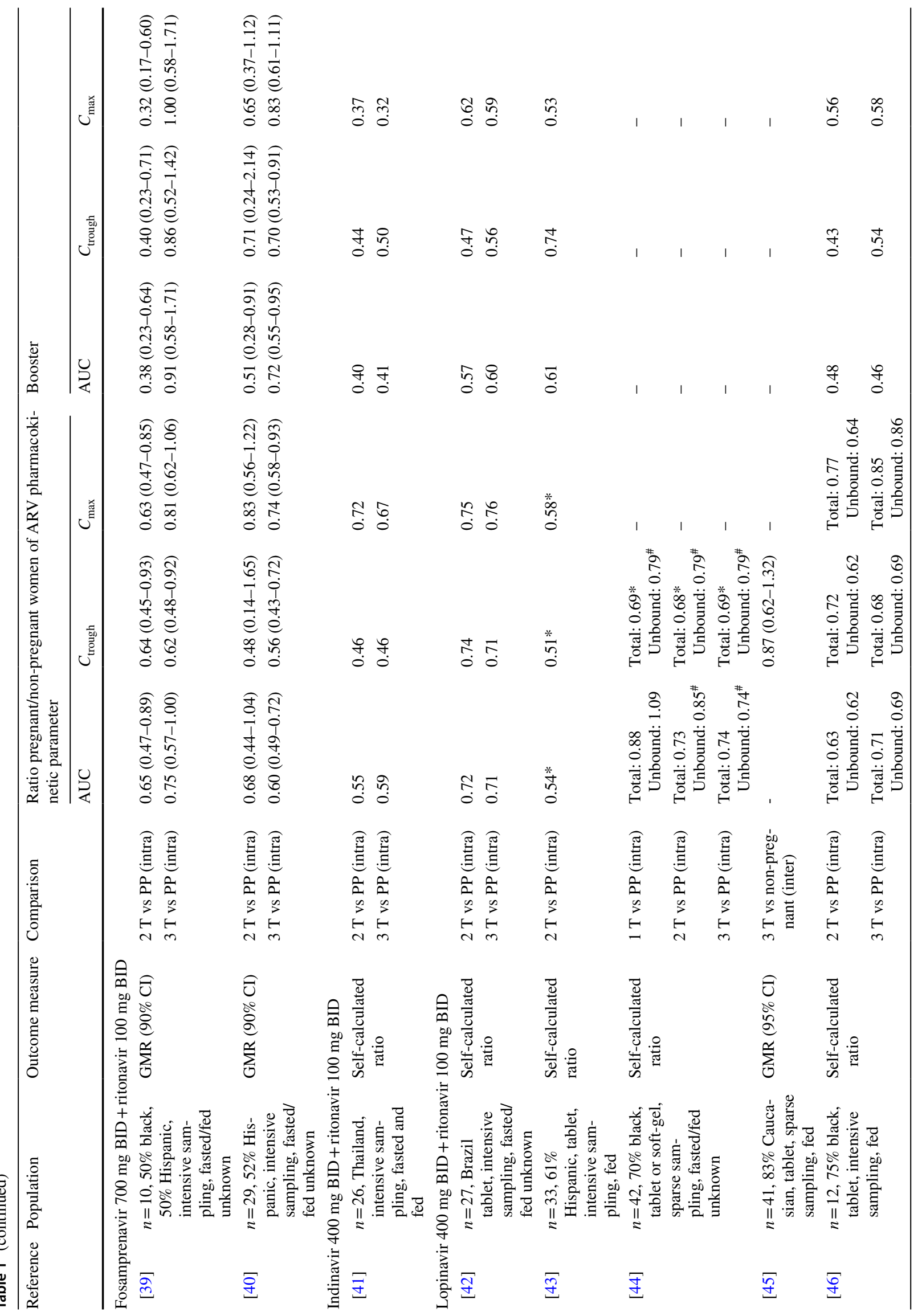




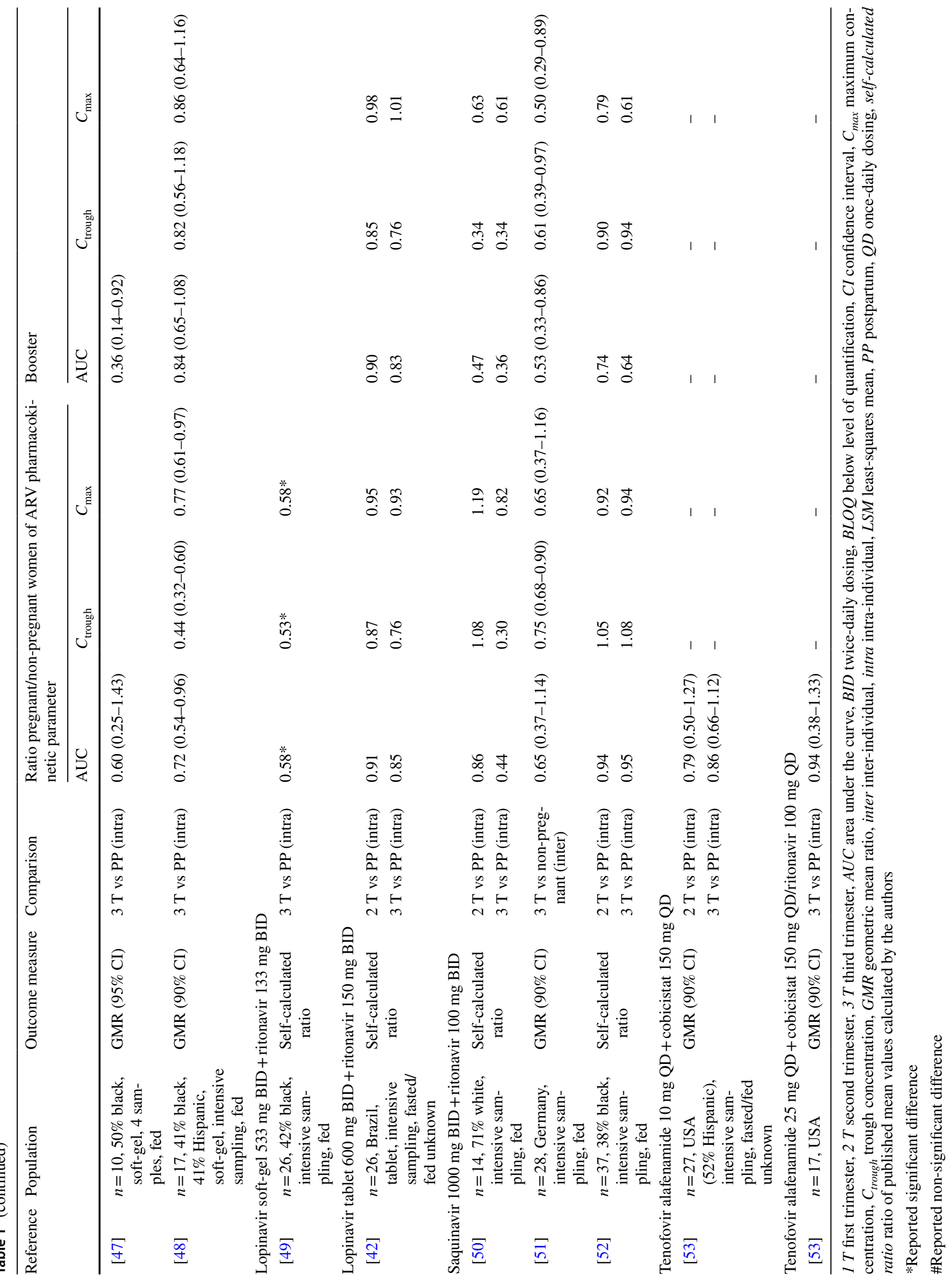




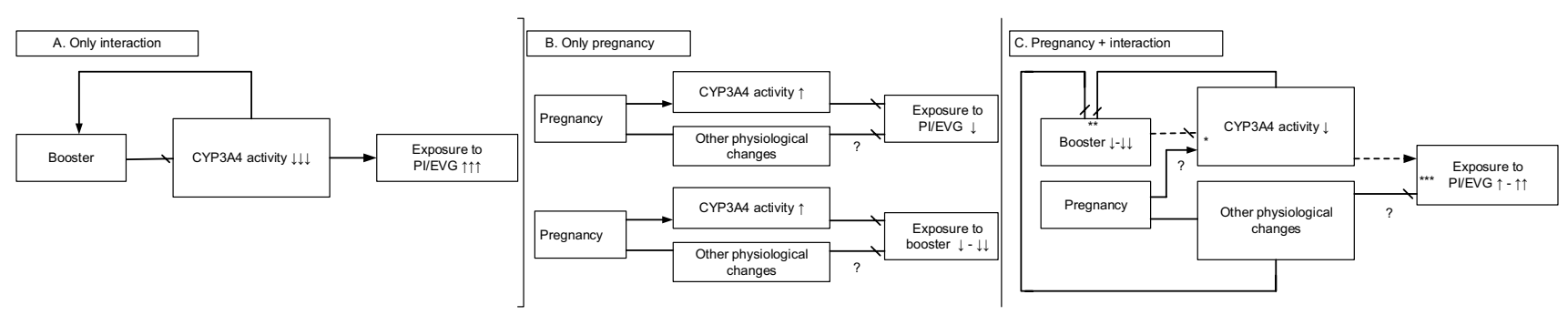

Fig. 1 Hypothesis of the drug-drug interaction of protease inhibitors (PIs)/elvitegravir (EVG) and boosters in pregnant women explained using three situations. The depicted situations are in comparison to $\mathrm{PI} / \mathrm{EVG}$ exposure in non-pregnant women without booster co-treatment. a Co-treatment with boosters increases PI/EVG exposure in non-pregnant individuals. b Physiological changes by pregnancy are expected to decrease PI/EVG exposure, as well as booster exposure.

trough concentrations $<0.05 \mathrm{mg} / \mathrm{L}$ during the dosing interval $[33,35,38,61]$. Cobicistat exposure is significantly decreased in the third trimester compared with non-pregnant women resulting in a decreased cobicistat-boosting effect [36]. Conversely, ritonavir trough concentrations in pregnant women do still exceed the half maximal inhibitory concentration for CYP3A4 inhibition of $0.08 \mathrm{mg} / \mathrm{L}$ after twice-daily dosing $[25,39,42,43,46,48,50,51,61,62]$, although not after once-daily dosing [17, 19, 21, 22, 25, 28].

Second, ritonavir is a more robust booster as CYP3A4 inhibition by ritonavir may last at reduced exposures. A dose reduction from 100 to $50 \mathrm{mg}$ of ritonavir has been shown to cause no change in saquinavir concentrations and did not affect ATV concentrations (median [interquartile range] ATV $C_{\text {trough }} 0.13[0.10-0.23]$ and $0.16[0.11-0.21] \mathrm{mg} / \mathrm{L}$ for $100 \mathrm{mg}$ and $50 \mathrm{mg}$ of ritonavir, respectively) [63, 64]. In contrast, a dose reduction from 150 to $100 \mathrm{mg}$ in cobicistat has been shown to substantially influence ATV concentrations (mean [\% coefficient of variation] ATV $C_{\text {tau }} 0.13$ [42.7\%] and 0.08 [58.8\%] $\mathrm{mg} / \mathrm{L}$ for $150 \mathrm{mg}$ and $100 \mathrm{mg}$ of cobicistat, respectively) [65]. Boosting by ritonavir has also been shown to be more robust in the presence of inducers like ETR. No clinically significant DDI was observed when co-administering ETR with DRV/ritonavir whereas ETR caused a significant decrease in DRV/cobicistat $C_{\text {trough }}$ [66-68].

Third, both boosters are highly protein bound, and for ritonavir similar unbound ("active") concentrations have been repeatedly reported in pregnancy [22, 36, 46]. Despite a large decrease in total ritonavir concentrations, unbound ritonavir concentrations are similar in pregnancy, this indicates that the driver for altered total ritonavir concentrations is the altered protein binding in pregnancy [69]. For cobicistat, this is still unclear, but a case report suggests similar unbound cobicistat concentrations during pregnancy as well [36]. Altogether, available data suggest that ritonavir boosting is more robust during pregnancy compared with cobicistat. c Co-treatment with a booster in pregnant women increases the PI/ EVG exposure, although less than in non-pregnant women because of a decreased booster exposure resulting in less cytochrome P450 (CYP) 3A4 inhibition. indicates a positive effect, + indicates a negative effect, - indicates causes, - - > indicates a decreased positive effect, --l-indicates a decreased negative effect, *,** and *** show inter-related effects

Although there is a clinically different interaction in pregnant women taking a cobicistat-boosted regimen, some experts also believe that the result of pregnancyrelated physiological changes are clinically relevant for some ritonavir-boosted regimens [70, 71]. Alternative dosing regimens are recommended for ritonavir-boosted $\mathrm{ATV}, \mathrm{DRV}$, and lopinavir to ensure an adequate $C_{\text {trough }}$ during pregnancy $[70,71]$. Because of the abundance of alternative regimens, no increased dose of EVG or additional cobicistat dosing has been evaluated in pregnant women treated with a cobicistat-boosted EVG-based regimen. However, it would be interesting to evaluate whether dosing modification of EVG or cobicistat leads to adequate EVG exposure during pregnancy.

\subsection{Enzyme Induction}

\subsubsection{Efavirenz and Lumefantrine}

Adegbola et al. examined the DDI between the antiretroviral EFV and the antimalarial LF in pregnant women compared to women postpartum [72]. Lumefantrine is primarily metabolized by CYP3A4 and EFV induces CYP3A4 activity, resulting in a decreased LF exposure in non-pregnant patients as showed in Fig. 2a [72, 73]. Pregnant women treated with LF have $~ 30 \%$ lower LF concentrations at day 7, a marker for therapeutic efficacy, compared with nonpregnant women [74-77]. A higher metabolic or elimination rate was observed in some of the pharmacokinetic studies, indicating induced CYP3A4 activity during pregnancy [14, 75-77]. Altered distribution of the lipophilic LF is also hypothesized to decrease LF exposure during pregnancy and is represented by other physiological changes in Fig. 2b [74]. The study of Adegbola et al. also showed that the EFV middose concentration $(\mathrm{C} 12 \mathrm{~h})$ significantly decreased in pregnant women treated with EFV compared with non-pregnant women (median $1820 \mathrm{ng} / \mathrm{mL}$ vs $2760 \mathrm{ng} / \mathrm{mL}$, respectively). 
The largest study of EFV pharmacokinetics during pregnancy showed a more modest effect. The 24-h concentration was significantly and marginally lowered during pregnancy (geometric mean ratio [90\% CI] 0.92 [0.77-1.09], $p=0.01$ ), while no-effect on the $\mathrm{AUC}_{0-24 \mathrm{~h}}$ was seen (geometric mean ratio [90\% CI] 1.09 [0.90-1.32]) [78]. This modest reduction in EFV pharmacokinetics is supported by other intensive pharmacokinetic studies and occurs possibly because of decreased plasma proteins or CYP2B6 induction as depicted in Fig. 2b [79, 80].

A smaller reduction in LF exposure is surprisingly observed in pregnant women compared with postpartum co-treated with EFV in the study of Adegbola et al. This suggests that the magnitude of the DDI is mitigated during pregnancy. The authors hypothesized that the reduced EFV exposure during pregnancy may lead to less CYP3A4 induction, as shown in Fig. 2c. This suggests that the decreased CYP3A4 induction by EFV is not compensated by the hormone-related CYP3A4 induction in pregnancy (Fig. 2c). Although CYP3A4 induction by EFV has been showed to be concentration dependent, it is debated if the modest EFV during pregnancy leads to less induction of CYP3A4 [81]. The lack of an appropriate control group in the study by Adegbola et al. may have led to an inadequate conclusion. Efavirenz is primarily metabolized by CYP2B6 and the CYP2B6 metabolizer status of the pregnant and nonpregnant control group was not determined. Possibly, the non-pregnant control group consisted of more CYP2B6 slow metabolizers leading to higher EFV concentrations, which is correlated with lower LF concentrations [82].

Importantly, a considerable proportion of pregnant women were shown to have a LF concentration 7 days postdrug intake below the $280-\mathrm{ng} / \mathrm{mL}$ cut-off previously considered for LF therapeutic efficacy [82]. Thus, the DDI between $\mathrm{EFV}$ and LF remains clinically relevant in pregnant women.

\subsubsection{Efavirenz plus an Anti-Tuberculosis Drug: Additional Influence of Genotype}

The CYP-metabolizing genotype may also influence the clinical significance of a DDI in pregnant women. This is illustrated by the example of EFV, isoniazid, and rifampicin. Efavirenz is metabolized predominantly by CYP2B6 and to a lesser extent by CYP2A6 and CYP3A4. Efavirenz plasma concentrations are highly variable, and most variability can be explained by the CYP2B6 genotype [83].

Co-treatment with rifampicin, a CYP inducer, was shown to decrease EFV concentrations modestly and to increase inter-patient variability as shown in Fig. 3a [83, 84]. The effect of rifampicin was shown to vary depending on the CYP2B6 genotype; in patients with an extensive CYP2B6 genotype, rifampicin caused a larger DDI magnitude [85]. Current treatment guidelines suggest that a dose adjustment of EFV is not necessary in the general population [83]. In pregnant women, EFV exposure is modestly decreased likely as a result of CYP2B6 induction and decreased plasma proteins and does not warrant a dose adjustment (Fig. 3b) [79, 80]. However, Dooley et al. demonstrated that pregnant women with an extensive CYP2B6 genotype are at a particular high risk for low EFV concentrations [83] and, therefore, this special patient population might require an increase in EFV dose. The cumulative effects of rifampicin interaction, physiological pregnancy alterations, and an extensive CYP2B6 genotype may result in a clinically relevant interaction (Fig. 3d). It has been reported that $36 \%$ of the pregnant women treated with rifampicin, isoniazid, and EFV had a minimum concentration $<1 \mu \mathrm{g} / \mathrm{mL}$, compared with $23 \%$ of the pregnant women not treated with tuberculosis drugs [83]. Thus, the modest DDI between EFV and rifampicin may become relevant in pregnant women with an extensive CYP2B6 genotype, justifying an EFV dose increase. Additionally, the magnitude of the EFV and rifampicin DDI may be increased as rifampicin exposure is modestly increased

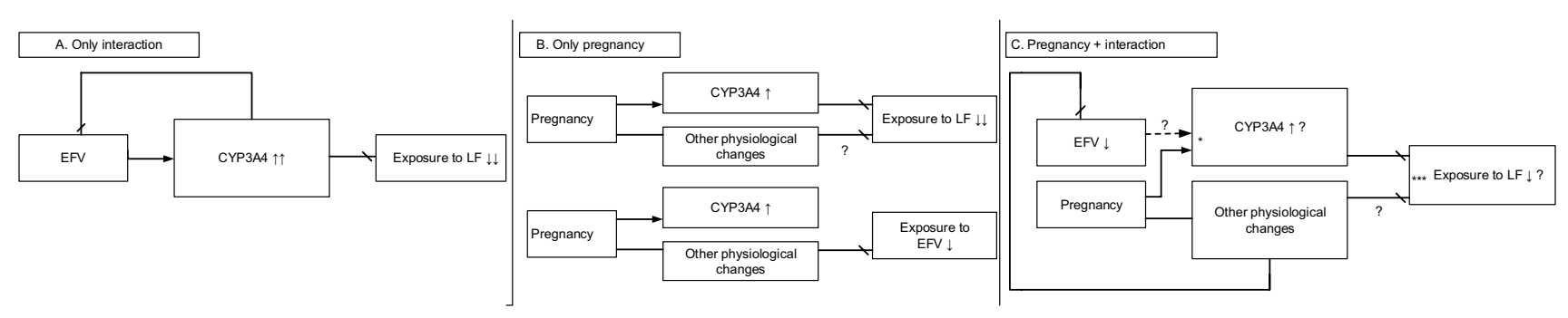

Fig. 2 Hypothesis of the drug-drug interaction of efavirenz (EFV) and lumefantrine (LF) in pregnant women explained using three situations. The depicted situations are in comparison to EFV exposure in non-pregnant women without the drug-drug interaction. a Co-treatment with EFV decreases LF exposure. b Physiological changes by pregnancy decrease LF exposure, as well as EFV exposure slightly. c Co-treatment with EFV in pregnant women decreases the LF exposure less than in non-pregnant women because of a decreased EFV exposure. indicates a positive effect, + indicates a negative effect, indicates causes, - -> indicates a decreased positive effect, ${ }^{*}, * *$ and *** show inter-related effects 
during pregnancy, possibly as a result of decreased clearance due to cholestatic changes [86].

Isoniazid, a CYP2A6 inhibitor, may further increase EFV concentrations in pregnant women with a CYP2B6 slowmetabolizer genotype, as in this situation CYP2A6 metabolism becomes more relevant [83]. A median minimum concentration of $6.54 \mu \mathrm{g} / \mathrm{mL}$ has indeed been reported in co-infected pregnant women with a slow-metabolizer genotype receiving tuberculosis treatment, making EFV-related side effects of concern [83].

\subsection{Transporter Inhibition}

\subsubsection{Etravirine and Tenofovir Disoproxil Fumarate: An Additional Compartment}

Another pitfall is that additional interactions may exist during pregnancy because an additional compartment is present in pregnant women: the fetus. Transplacental transport to the fetus is susceptible to DDIs. Research showed for example that ETR inhibits placental ABC transporter BCRP (ABCG2) in vitro, and ritonavir inhibits several placental $\mathrm{ABC}$ transporters at physiological concentrations [87, 88]. Etravirine and ritonavir can, therefore, increase the fetal exposure of co-administered PIs or lamivudine, which are known substrates of the placental $\mathrm{ABC}$ transporters [88].

\subsubsection{Cobicistat and Tenofovir Alafenamide}

Although cobicistat is contraindicated in pregnancy since 2018, we discuss this interaction as this provides insight into transporter interactions during pregnancy. Interaction data in pregnancy are available from prior to 2018 . When combined with cobicistat, TAF exposure is strongly increased by the inhibition of efflux transporter proteins in the gastrointestinal tract (i.e., P-glycoprotein and breast cancer resistance protein) as shown in Fig. 4a [7]. Therefore, a dose reduction from 25 to $10 \mathrm{mg}$ of TAF is recommended in patients co-treated with cobicistat in fixed-dose combinations [89]. In contrast to this interaction, pregnancy-related physiological changes decrease TAF exposure (Fig. 4b); TAF exposure decreased by approximately $35 \%$ in the third trimester in women treated with $25 \mathrm{mg}$ of unboosted TAF [53, 90]. This decrease probably does not result from an alteration in transporter activity as indicated by an animal study showing similar P-glycoprotein activity in pregnant and non-pregnant mice [14].

In the combined situation of pregnant women co-treated with cobicistat, there is a marginal and insignificant decrease in TAF exposure compared with postpartum, see Table 1 and Fig. $4 \mathrm{c}[53,90,91]$. This suggests that the DDI compensates for the reduced exposure as a result of the physiological pregnancy changes (Fig. 4b). Theoretically, this is inconsequent because cobicistat exposure is greatly reduced during pregnancy, as mentioned earlier. Possibly the magnitude of the DDI is not influenced by physiological pregnancy changes and the decreased cobicistat exposure. The intestinal transporter inhibition by cobicistat might be caused by local (intestinal) cobicistat concentrations, and to a lesser extent by (decreased) systemic cobicistat concentrations [92]. This inconsistency can also be explained by the large variability and uncertainty in these data because TAF plasma concentrations are difficult to measure and often below the limit of quantification. It is unclear yet whether the intracellular concentration of the active tenofovir anabolite is sustained during pregnancy.

The clinical significance of the interaction between TAF and cobicistat is lower in pregnant compared with non-pregnant women. The exposure of TAF is similar in pregnant women co-treated with TAF $25 \mathrm{mg}$ and cobicistat (median $\mathrm{AUC}_{0-24 \mathrm{~h}} 335 \mathrm{ng} * \mathrm{~h} / \mathrm{mL}$ [91]) and non-pregnant patients treated with TAF $25 \mathrm{mg}$ (median $\mathrm{AUC}_{0-24 \mathrm{~h}} 308 \mathrm{ng} * \mathrm{~h} / \mathrm{mL}$ [93]), which is considered to be a safe and regular treatment option. Based on these limited data, TAF exposure is not clinically significantly altered in pregnant women co-treated with cobicistat.

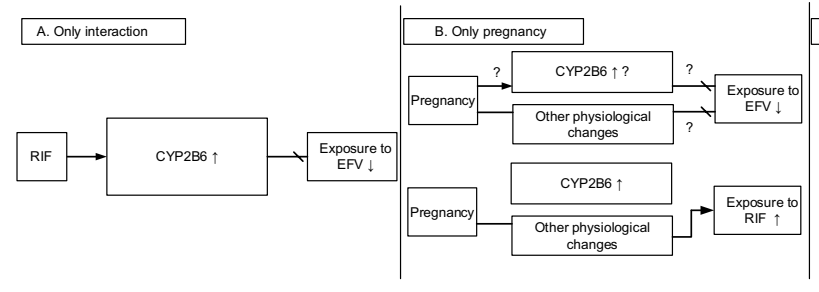

Fig. 3 Hypothesis of the drug-drug interaction of efavirenz (EFV) and rifampicin (RIF) in pregnant women with an extensive cytochrome P450 (CYP) 2B6 genotype explained using four situations. The depicted situations are in comparison to EFV exposure in non-pregnant women without the drug-drug interaction. a Co-treatment with RIF decreases EFV exposure. b Physiological changes by pregnancy decrease EFV exposure slightly, and increase RIF

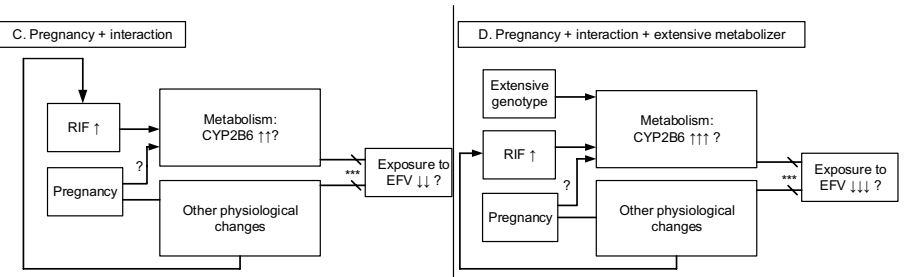

exposure slightly [86]. c Co-treatment with RIF in pregnant women decreases the EFV exposure more than in non-pregnant women. d Co-treatment with RIF in pregnant women and an extensive CYP2B6 genotype decreases the EFV exposure even more, owing to a higher CYP metabolism activity. indicates a positive effect, + indicates a negative effect, $*$, ** and $* * *$ show inter-related effects 

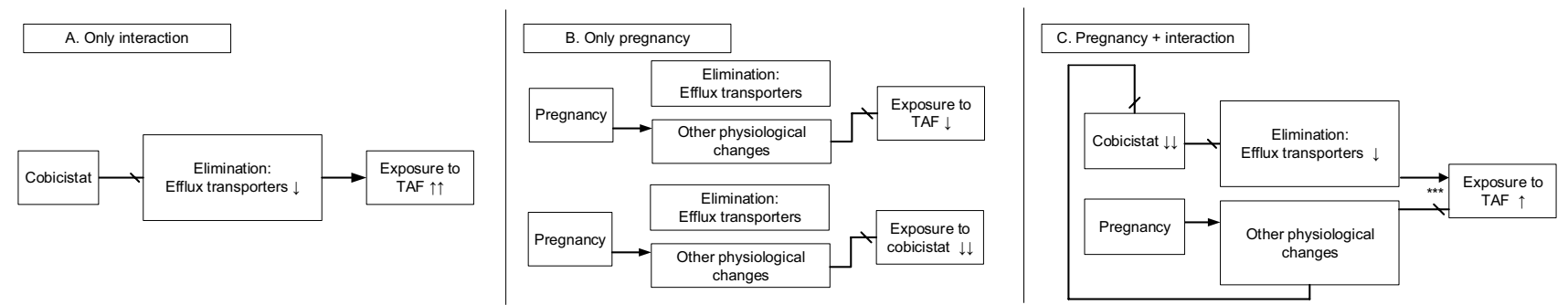

Fig. 4 Hypothesis of the drug-drug interaction of cobicistat and tenofovir alafenamide (TAF) in pregnant women explained using three situations. The depicted situations are in comparison to TAF exposure in non-pregnant women without co-treatment with boosters. a Co-treatment with cobicistat increases TAF exposure. b Physiological changes by pregnancy decrease TAF exposure, as well as cobi-

\subsection{Unknown Mechanism}

\subsubsection{Tenofovir Disoproxil Fumarate and Atazanavir}

Several studies examined the DDI between TDF and ATV in pregnant women. Most studies observed a 25\% decrease in ATV exposure in non-pregnant patients co-treated with TDF [94-96], but a non-altered ATV exposure was also observed in one study [97]. The mechanisms of this DDI is unknown until today. As tenofovir (TFV) is renally cleared and ATV undergoes CYP-mediated metabolism, an interaction at the biotransformation level is unlikely. The DDI could possibly occur at the absorption level as a result of induction of intestinal P-glycoprotein by TFV or owing to a physiochemical interaction in the gut [94].

A decrease in ATV exposure has also been confirmed in pregnant women living with HIV, as shown in Table 2 and depicted in Fig. 5b [18-21]. The ATV exposure is likely decreased in pregnant women owing to a combination of decreased absorption, increased clearance, and reduced booster exposure [19]. Tenofovir exposure is also decreased during pregnancy because of an increased volume of distribution and increased renal excretion [98, 99]. Three studies confirmed that the ATV exposure is lower in pregnant women treated with a TDF-based regimen compared with both non-pregnant women co-treated with a TDF-based regimen and pregnant women co-treated with a non TDF-based regimen, see Table 2 and Fig. 5c [18, 19, 21].

The magnitude of the DDI does not seem to change during pregnancy based on our recent data and third-trimester data from Mirochnick et al. (Table 2) [18, 21]. Interestingly, the study of Kreitchmann et al. reports a change in the magnitude of DDIs during pregnancy, which seems to relate to non-adherence in the non-TDF arm in this study [19]. Thus, the similar DDI magnitude in pregnant women, despite the reduced TFV exposure, suggests that this DDI is not concentration dependent. This supports the hypothesis of cistat exposure. c Co-treatment with cobicistat in pregnant women increases the TAF exposure, but this increase is less than in non-pregnant women with a cobicistat-boosted regimen (situation 4A). indicates a positive effect, + indicates a negative effect, $*, * *$ and $* * *$ show inter-related effects

a local interacting effect of TDF on the absorption of ATV. Furthermore, if the DDI is not influenced by physiological changes in pregnancy, there is probably no competing effect of pregnancy and TFV on ATV absorption (Fig. 5c).

Although the extent of the interaction is similar in nonpregnant and pregnant women, the cumulative effect of physiological pregnancy changes (Fig. 5c) and the DDI lead to a more clinically significant DDI during pregnancy. Lower ATV $C_{\text {trough }}$ is observed in pregnant women with the DDI; a geometric mean $(95 \% \mathrm{CI})$ of $0.44(0.31-0.62) \mathrm{mg} /$ $\mathrm{mL}$ is observed in pregnant women co-treated with ATV and TDF vs a geometric mean (95\% CI) of $0.89(0.59-1.32) \mathrm{mg} /$ $\mathrm{mL}$ in non-pregnant women co-treated with ATV and TDF. Nevertheless, co-treatment with ATV and TDF is not contraindicated during pregnancy because the observed $C_{\text {trough }}$ is not lower than the $0.15-\mathrm{mg} / \mathrm{L}$ cut-off value considered for therapeutic efficacy [100, 101].

\subsubsection{Nevirapine and Mefloquine}

Haaland et al. examined ARV plasma concentrations in a group of pregnant women living with HIV co-treated with mefloquine, which showed a high rate of mother-to-child transmission [102]. A significant reduction in median nevirapine concentrations (approximately 25\%) was observed in pregnant women receiving co-treatment with mefloquine, although the nevirapine concentrations remained above the previously reported target values to prevent HIV replication [102]. This reduction was not observed in pregnant women receiving nevirapine with placebo. The mechanism of this DDI remains unclear, and the DDI may be observed in pregnant women owing to pregnancy-related physiological changes that could amplify the magnitude of the DDI. This interaction has never been examined in non-pregnant women, and, therefore, the magnitude of the DDI in the nonpregnant situation is unknown. Despite adequate nevirapine trough concentrations, more mother-to-child transmissions 


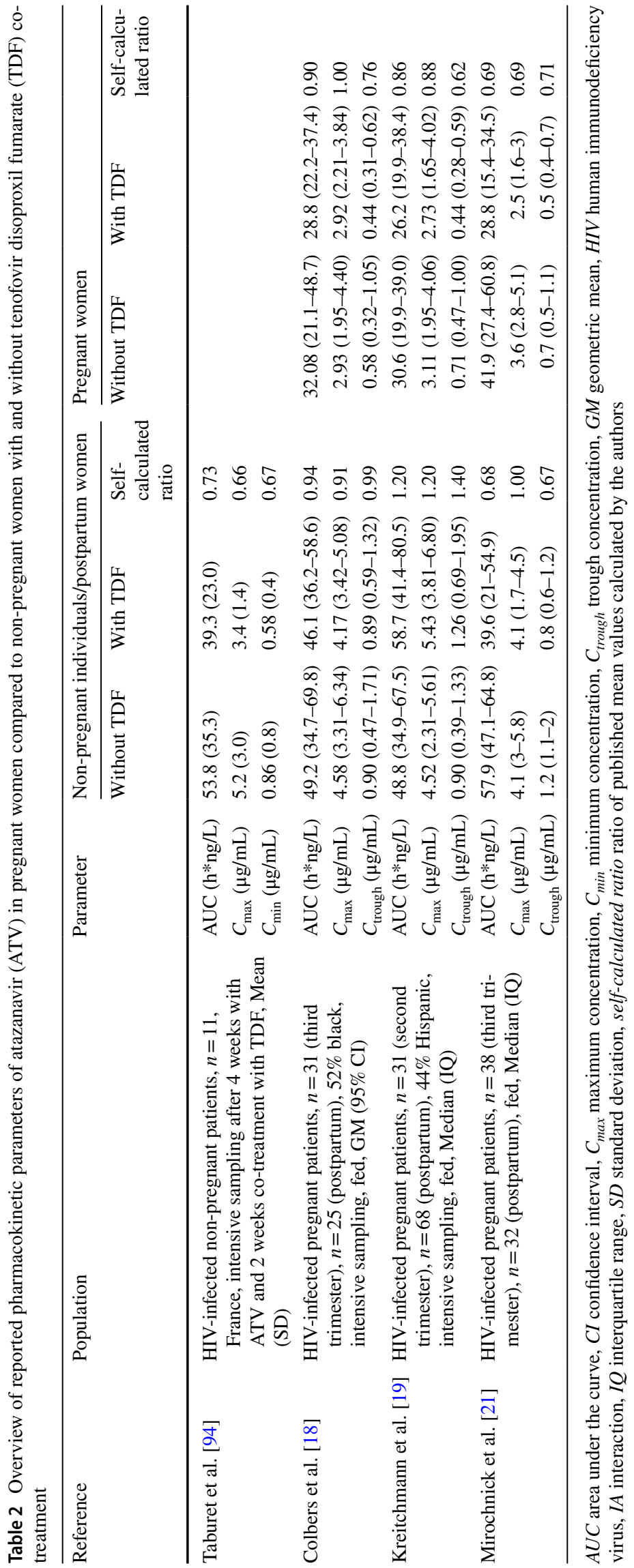




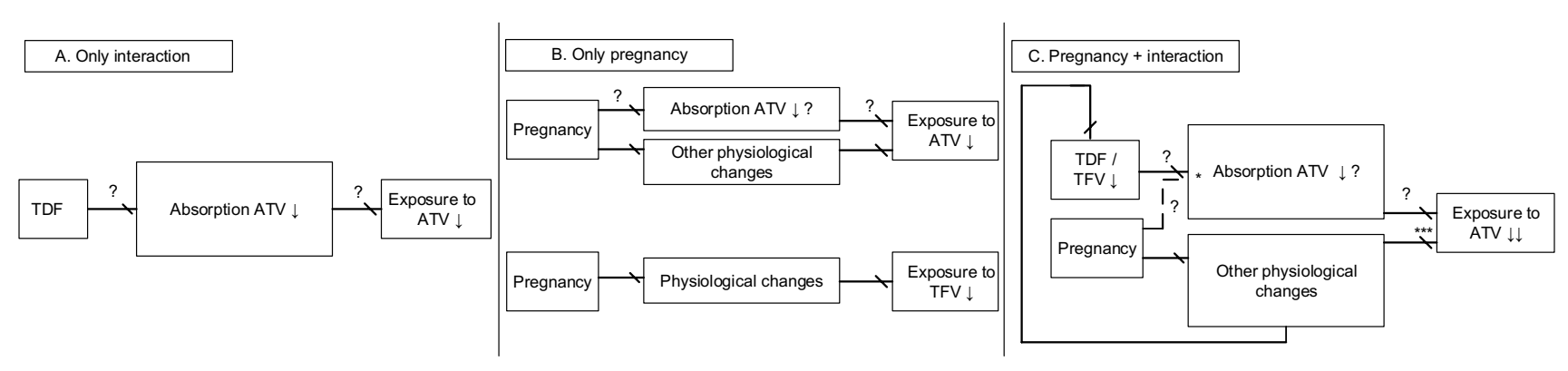

Fig. 5 Hypothesis of the drug-drug interaction of tenofovir disoproxil fumarate (TDF) and atazanavir (ATV) in pregnant women explained using three situations. The depicted situations are in comparison to ATV exposure in non-pregnant women without tenofovir (TFV) co-administration. a Co-treatment with TDF decreases ATV exposure. b Physiological changes by pregnancy decrease ATV exposure, as well as TFV exposure. c Co-treatment with TDF in pregnant

were observed, making this DDI likely of clinical relevance for HIV and malaria co-infected pregnant women.

\section{Common Unstudied Interactions in Pregnant Women Living with HIV}

Other commonly used drugs in pregnancy that can interact with ARV include: proton pump inhibitors, iron and mineral supplements, antacids, domperidone, and macrolide antibiotics [103, 104]. Drug-drug interactions with these co-medications have not been studied in pregnant women, while having the potential for clinically relevant interactions. They also illustrate possibly altered interaction mechanisms during pregnancy at the level of distribution, absorption, and non-CYP metabolism.

For instance, caution is needed when interpreting serum concentrations of highly protein-bound ARVs (such as PIs and INSTIs) in pregnancy, especially when co-administered with other highly protein-bound drugs. A DDI at the level of distribution can theoretically change in pregnant women because the amount of plasma proteins decreases during pregnancy [14]. Competition for plasma proteins with a highly protein-bound concomitant drug and a decrease in plasma proteins can co-exist, resulting in even lower total ARV concentrations.

Another common DDI mechanism involves the chelation of INSTIs with divalent cations such as iron, requiring staggered administration $[8,105-110]$. The magnitude of the physiochemical interaction in the gut is not affected by physiological changes in pregnancy. However, this DDI is likely to be more clinically relevant in pregnant women because of the additive effects of chelation and pregnancy-related physiological changes potentially leading to a lower absolute INSTI exposure. Additionally, the time between INSTI and iron administration may need to be increased during women decreases the ATV exposure even more than in non-pregnant women because of the joined effects of the physiological changes in pregnancy and the interaction. The degree of interaction does not seem to change. indicates a positive effect, + indicates a negative effect, --- indicates likely negligible effect, $*, * *$ and $* * *$ show interrelated effects

pregnancy because gastrointestinal motility is decreased in pregnant women [14]. The limited decrease of raltegravir and dolutegravir (DTG) exposure in pregnant women is not considered to be of clinical significance [111-113], but may become of clinical significance in pregnant women cotreated with iron.

Furthermore, the common DDI between gastric acidneutralizing drugs and ATV or rilpivirine (RPV) is yet unstudied in pregnant women living with HIV. The absorption of RPV/ATV decreases with increasing gastric $\mathrm{pH}$, thus co-administration with proton pump inhibitors is contraindicated in non-pregnant women and it is recommended to stagger administration with histamine $\mathrm{H}_{2}$ antagonists (cimetidine, famotidine, ranitidine) [96, 114]. However, a different recommendation might be needed in pregnant women as pregnancy-related physiological changes include a possible increase in gastric $\mathrm{pH}$ that will also result in a decrease in RPV/ATV exposure [13,115-117]. Thus, it is possible that the absorption of ATV/RPV is worse in pregnant women treated with an $\mathrm{H}_{2}$ antagonist because of the additive effect of the drug- and pregnancy-related physiological changes on the gastric $\mathrm{pH}$. Research is needed to show if a contraindication for ATV/RPV and $\mathrm{H}_{2}$ antagonists is required in pregnant women.

Hepatic DDIs concerning non-CYP enzymes can be potentially altered during pregnancy as well. A common example is the DDI between rifampicin and DTG, as the prevalence of HIV-tuberculosis co-infection is high in third-world countries and DTG-containing regimens are preferred according to the World Health Organization guidelines [118]. Glucuronidation to the main metabolite of DTG is catalyzed by UGT1A1, which can be induced by rifampicin. A dose increase to $50 \mathrm{mg}$ of DTG twice daily is needed in non-pregnant individuals when co-administered with rifampicin $[118,119]$. In pregnant women, DTG exposure is modestly decreased and UGT1A1 induction and 
decreased plasma proteins have been suggested as causes $[111,120,121]$. It is still uncertain if UGT1A1 is induced during pregnancy [14], as some studies suggested UGT1A1 induction during pregnancy $[122,123]$, but an increased metabolic ratio of DTG-glucuronide/DTG could not be demonstrated in a small pharmacokinetic study with pregnant women using DTG [120]. In pregnant women co-treated with DTG and rifampicin, the effect of physiological pregnancy alterations and rifampicin UGT1A1 induction could increase, leading to a larger decrease in DTG exposure than in pregnant women without rifampicin. A larger DTG dose increase may be needed in pregnant women co-treated with rifampicin and DTG, but a pharmacokinetic assessment is needed for confirmation.

\section{Future Perspectives}

More research on DDIs in pregnant women is needed, but the study design remains challenging. Pregnancy pharmacology studies lend themselves to investigate DDIs, as well as the systematic collection of therapeutic drug monitoring samples. In both cases, accurate registration of co-medication, dose, and time of intake make it possible to determine the absolute exposure of ARVs in pregnant women with DDIs, but a sufficient sample size is crucial for the interpretation. Observational pharmacology studies in pregnancy generally focus on the exposure to the ARV; however, in the presence of potential DDIs with non-ARVs, the plasma concentration of these agents should be systematically determined. Physiologically based pharmacokinetic (PBPK) models have been applied to predict drug exposure in special populations and to simulate DDIs. The validity of pregnancy PBPK models has improved tremendously during the recent years owing to the increased interest in these models [124]. Although more in vitro and clinical studies are needed to fill knowledge gaps, for example on UGT and drug transporter activity, the models are already widely used to understand and predict pharmacokinetic changes during pregnancy [124]. The knowledge from DDI and pregnancy PBPK models can be combined to improve our understanding of this complex situation. In particular, DDIs on the level of placental drug transport are difficult to investigate in clinical studies as only sampling from the umbilical cord during delivery is considered to be ethical. Knowledge on pregnancy PBPK models including the placenta and the fetus is gained rapidly and a combination of these models can offer a solution for predicting placental drug transporter DDIs [125].

Clinically relevant DDIs apply to pregnant women, but are also a factor of consideration for other special patient population such as the elderly, children, and patients with hepatic impairment. The management of DDIs has to be conducted on an individual basis. In the era of precision medicine, DDIs cannot be ignored and are an opportunity for a more effective and individualized drug treatment. More attention is needed from both researchers and clinicians to demonstrate which DDIs are clinically relevant in special populations.

\section{Conclusions}

Drug-drug interactions in pregnant women remain a complex situation because the extent and clinical significance of a DDI can change during pregnancy. Only a few studies examined this complex situation; therefore, the management of DDIs in pregnant women is mostly based on theoretical assumptions. This makes decisions regarding the optimal dose and ARV regimen very difficult, and places pregnant women living with HIV and their newborns at risk.

The extent of a DDI can change during pregnancy, although it is very challenging, if not impossible, to distinguish the influence of individual processes. The extent of a DDI may differ if the exposure of the perpetrator changes during pregnancy as suggested for concentration-dependent DDIs such as the DDI between cobicistat and PIs/EVG (inhibition of metabolism). Drug-drug interactions at the level of intestinal transporters do not seem to be different in pregnant women (i.e., TAF co-administered with cobicistat).

More importantly, the clinical significance of most DDIs in this review changed during pregnancy when looking at the absolute drug exposure in pregnant women. The combined effects of the DDI and other pregnancy-related physiological changes may lead to a more pronounced reduction in drug exposure, thereby exposing to the risk of therapeutic failure. Only the DDI between cobicistat and PIs/EVG in pregnancy has led to a change in drug labels; currently, the use of cobicistat-boosted regimens in pregnancy is no longer recommended [16]. There are not enough data for the other reviewed DDIs to change the official recommendations, although some DDIs resulted in drug concentrations below the target values in a large proportion of the pregnant women.

\section{Compliance with Ethical Standards}

Funding No specific funding was received for the preparation of this article.

Conflict of interest DMB has received research grants to his institution from Merck, BMS, Janssen/Tibotec, ViiV Healthcare, and Gilead, has received educational grants from Merck, was a speaker for a symposia for Merck, and is a member of the advisory boards of ViiV Healthcare and Merck. VEB, AC, CM, and JM have no conflicts of interest that are directly relevant to the content of this article. 
Open Access This article is licensed under a Creative Commons Attribution-NonCommercial 4.0 International License, which permits any non-commercial use, sharing, adaptation, distribution and reproduction in any medium or format, as long as you give appropriate credit to the original author(s) and the source, provide a link to the Creative Commons licence, and indicate if changes were made. The images or other third party material in this article are included in the article's Creative Commons licence, unless indicated otherwise in a credit line to the material. If material is not included in the article's Creative Commons licence and your intended use is not permitted by statutory regulation or exceeds the permitted use, you will need to obtain permission directly from the copyright holder. To view a copy of this licence, visit http://creativecommons.org/licenses/by-nc/4.0/.

\section{References}

1. DHHS. Recommendations for the use of antiretroviral drugs in pregnant women with HIV infection and interventions to reduce perinatal HIV transmission in the United States. https://aidsinfo. nih.gov/guidelines/html/3/perinatal/0]. Accessed $20 \mathrm{Feb} 2020$.

2. Smith PF, DiCenzo R, Morse GD. Clinical pharmacokinetics of non-nucleoside reverse transcriptase inhibitors. Clin Pharmacokinet. 2001;40(12):893-905.

3. Malaty LI, Kuper JJ. Drug interactions of HIV protease inhibitors. Drug Saf. 1999;20(2):147-69.

4. US FDA. Rifadin: label 2019. https://www.accessdata.fda.gov/ drugsatfda_docs/label/2019/050420s083,050627s025lbl.pdf. Accessed 5 May 2020.

5. EMA. Stocrin: summary of product characteristics. 2014. https://www.ema.europa.eu/docs/en_GB/document_library/ EPAR_-_Product_Information/human/000250/WC50005894 6.pdf. Accessed 5 May 2020.

6. Renjifo B, van Wyk J, Salem AH, Bow D, Ng J, Norton M. Pharmacokinetic enhancement in HIV antiretroviral therapy: a comparison of ritonavir and cobicistat. AIDS Rev. 2015;17(1):37-46.

7. Lepist EI, Phan TK, Roy A, Tong L, Maclennan K, Murray B, et al. Cobicistat boosts the intestinal absorption of transport substrates, including HIV protease inhibitors and GS-7340, in vitro. Antimicrob Agents Chemother. 2012;56(10):5409-13. https:// doi.org/10.1128/aac.01089-12.

8. Song I, Borland J, Arya N, Wynne B, Piscitelli S. Pharmacokinetics of dolutegravir when administered with mineral supplements in healthy adult subjects. J Clin Pharmacol. 2015;55(5):490-6. https://doi.org/10.1002/jcph.439.

9. Klein CE, Chiu YL, Cai Y, Beck K, King KR, Causemaker SJ, et al. Effects of acid-reducing agents on the pharmacokinetics of lopinavir/ritonavir and ritonavir-boosted atazanavir. J Clin Pharmacol. 2008;48(5):553-62.

10. Palazzo A, Trunfio M, Pirriatore V, Milesi M, De Nicolo A, Alcantarini C, et al. Lower dolutegravir plasma concentrations in HIV-positive patients receiving valproic acid. J Antimicrob Chemother. 2018;73(3):826-7. https://doi.org/10.1093/jac/dkx46 1.

11. Colbers A, Greupink R, Burger D. Pharmacological considerations on the use of antiretrovirals in pregnancy. Curr Opin Infect Dis. 2013;26(6):575-88. https://doi.org/10.1097/QCO.00000 00000000017.

12. Parry E, Shields R, Turnbull AC. Transit time in the small intestine in pregnancy. J Obstet Gynaecol Br Commonw. 1970;77(10):900-1. https://doi.org/10.1111/j.1471-0528.1970. tb03423.x.
13. Loebstein R, Lalkin A, Koren G. Pharmacokinetic changes during pregnancy and their clinical relevance. Clin Pharmacokinet. 1997;33(5):328-43.

14. Anderson GD. Pregnancy-induced changes in pharmacokinetics: a mechanistic-based approach. Clin Pharmacokinet. 2005;44(10):989-1008.

15. Dawes M, Chowienczyk PJ. Drugs in pregnancy: pharmacokinetics in pregnancy. Best Pract Res Clin Obstet Gynaecol. 2001;15(6):819-26.

16. Boyd SD, Sampson MR, Viswanathan P, Struble KA, Arya V, Sherwat AI. Cobicistat-containing antiretroviral regimens are not recommended during pregnancy: viewpoint. AIDS. 2019;33(6):1089-93. https://doi.org/10.1097/qad.0000000000 002163 .

17. Le MP, Mandelbrot L, Descamps D, Soulie C, Ichou H, Bourgeois-Moine A, et al. Pharmacokinetics, safety and efficacy of ritonavir-boosted atazanavir (300/100 mg once daily) in HIV1-infected pregnant women. Antivir Ther. 2015;20(5):507-13. https://doi.org/10.3851/IMP2936.

18. Colbers A, Hawkins D, Hidalgo-Tenorio C, van der Ende M, Gingelmaier A, Weizsacker K, et al. Atazanavir exposure is effective during pregnancy regardless of tenofovir use. Antivir Ther. 2015;20(1):57-64. https://doi.org/10.3851/IMP2820.

19. Kreitchmann R, Best BM, Wang J, Stek A, Caparelli E, Watts $\mathrm{DH}$, et al. Pharmacokinetics of an increased atazanavir dose with and without tenofovir during the third trimester of pregnancy. J Acquir Immune Defic Syndr. 2013;63(1):59-66. https://doi. org/10.1097/QAI.0b013e318289b4d2.

20. Conradie F, Zorrilla C, Josipovic D, Botes M, Osiyemi $\mathrm{O}$, Vandeloise E, et al. Safety and exposure of once-daily ritonavir-boosted atazanavir in HIV-infected pregnant women. HIV Med. 2011;12(9):570-9. https://doi.org/10.111 1/j.1468-1293.2011.00927.x.

21. Mirochnick M, Best BM, Stek AM, Capparelli EV, Hu C, Burchett SK, et al. Atazanavir pharmacokinetics with and without tenofovir during pregnancy. J Acquir Immune Defic Syndr. 2011;56(5):412-9. https://doi.org/10.1097/QAI.0b013e3182 0fd093.

22. Foca E, Calcagno A, Bonito A, Simiele M, Domenighini E, D'Avolio A, et al. Atazanavir intracellular concentrations remain stable during pregnancy in HIV-infected patients. J Antimicrob Chemother. 2017;72(11):3163-6. https://doi.org/10.1093/jac/ dkx274.

23. Ripamonti D, Cattaneo D, Maggiolo F, Airoldi M, Frigerio L, Bertuletti P, et al. Atazanavir plus low-dose ritonavir in pregnancy: pharmacokinetics and placental transfer. AIDS. 2007;21(18):2409-15.

24. Momper JD, Stek A, Shapiro D, Smith E, Chakhtoura N, Capparelli E, et al. Pharmacokinetics of atazanavir boosted with cobicistat during pregnancy and postpartum [abstract no. 10]. In: 20th International Workshop on Clinical Pharmacology of HIV, Hepatitis and Other Antiviral Drugs; 14-16 May 2019; Noodwijk.

25. Colbers A, Molto J, Ivanovic J, Kabeya K, Hawkins D, Gingelmaier A, et al. Pharmacokinetics of total and unbound darunavir in HIV-1-infected pregnant women. J Antimicrob Chemother. 2015;70(2):534-42. https://doi.org/10.1093/jac/dku400.

26. Stek A, Best BM, Wang J, Capparelli EV, Burchett SK, Kreitchmann R, et al. Pharmacokinetics of once versus twice daily darunavir in pregnant HIV-infected women. J Acquir Immune Defic Syndr. 2015;70(1):33-41. https://doi.org/10.1097/QAI.00000 00000000668

27. Zorrilla CD, Wright R, Osiyemi OO, Yasin S, Baugh B, Brown $\mathrm{K}$, et al. Total and unbound darunavir pharmacokinetics in pregnant women infected with HIV-1: results of a study of 
darunavir/ritonavir 600/100 mg administered twice daily. HIV Med. 2014;15(1):50-6. https://doi.org/10.1111/hiv.12047.

28. Crauwels HM, Kakuda TN, Ryan B, Zorrilla C, Osiyemi $\mathrm{OO}$, Yasin S, et al. Pharmacokinetics of once-daily darunavir/ritonavir in HIV-1-infected pregnant women. HIV Med. 2016;17(9):643-52. https://doi.org/10.1111/hiv.12366.

29. Lambert J, Jackson V, Else L, Lawless M, McDonald G, Le Blanc DM, et al. Darunavir pharmacokinetics throughout pregnancy and postpartum. J Int AIDS Soc. 2014;17(4 Suppl. 3):19485. https://doi.org/10.7448/ias.17.4.19485.

30. Curran A, Ocana I, Deig E, Guiu J, Lopez RM, Perez M, et al. Darunavir/ritonavir once daily total and unbound plasmatic concentrations in HIV-infected pregnant women [abstract no. P-19]. In: 14th International Workshop on Clinical Pharmacology of HIV Therapy; 2013; Amsterdam.

31. Murtagh R, Else LJ, Kuan KB, Khoo SH, Jackson V, Patel A, et al. Therapeutic drug monitoring of darunavir/ritonavir in pregnancy. Antivir Ther. 2019;24(3):229-33. https://doi. org/10.3851/imp3291.

32. Eke AC, Stek AM, Wang J, Kreitchmann R, Shapiro DE, Smith E, et al. Darunavir pharmacokinetics with an increased dose during pregnancy. J Acquir Immune Defic Syndr. 2020;83(4):373-80. https://doi.org/10.1097/qai.0000000000 002261 .

33. Crauwels HM, Osiyemi O, Zorrilla C, Bicer C, Brown K. Reduced exposure to darunavir and cobicistat in HIV-1-infected pregnant women receiving a darunavir/cobicistat-based regimen. HIV Med. 2019;20(5):337-43. https://doi.org/10.1111/hiv.12721

34. Momper JD, Best B, Wang J, Stek A, Shapiro D, George K, et al. Pharmacokinetics of darunavir boosted with cobicistat during pregnancy and postpartum [abstract no. WEPEB1182018]. In: 22nd International AIDS Conference; 23-27 July 2018; Amsterdam.

35. Momper JD, Best BM, Wang J, Capparelli EV, Stek A, Barr E, et al. Elvitegravir/cobicistat pharmacokinetics in pregnant and postpartum women with HIV. AIDS. 2018;32(17):2507-16. https ://doi.org/10.1097/qad.0000000000001992.

36. Marzolini C, Decosterd L, Winterfeld U, Tissot F, Francini K, Buclin T, et al. Free and total plasma concentrations of elvitegravir/cobicistat during pregnancy and postpartum: a case report. $\mathrm{Br}$ J Clin Pharmacol. 2017;83(12):2835-8. https://doi.org/10.1111/ bcp. 13310 .

37. Schalkwijk S, Colbers A, Konopnicki D, Greupink R, Russel FG, Burger D, et al. First reported use of elvitegravir and cobicistat during pregnancy. AIDS. 2016;30(5):807-8. https://doi. org/10.1097/QAD.0000000000000976.

38. Bukkems V, Necsoi C, Tenorio CH, Garcia C, Rockstroh J, Schwarze-Zander C, et al. Clinically significant lower elvitegravir exposure during third trimester of pregnant patients living with HIV: data from the PANNA study. Clin Infect Dis. 2020 Apr;24(ciaa48):2020. https://doi.org/10.1093/cid/ciaa488.

39. Cespedes MS, Castor D, Ford SL, Lee D, Lou Y, Pakes GE, et al. Steady-state pharmacokinetics, cord blood concentrations, and safety of ritonavir-boosted fosamprenavir in pregnancy. $\mathrm{J}$ Acquir Immune Defic Syndr. 2013;62(5):550-4. https://doi.org/10.1097/ QAI.0b013e318285d918.

40. Eke AC, Wang J, Amin K, Shapiro DE, Stek A, Smith E, et al. Fosamprenavir with ritonavir pharmacokinetics during pregnancy. Antimicrob Agents Chemother. 2020 Mar 24;64(4):e02260-e2261. https://doi.org/10.1128/aac.02260-19.

41. Cressey TR, Best BM, Achalapong J, Stek A, Wang J, Chotivanich N, et al. Reduced indinavir exposure during pregnancy. $\mathrm{Br}$ J Clin Pharmacol. 2013;76(3):475-83. https://doi.org/10.1111/ bcp. 12078 .
42. Santini-Oliveira M, Estrela Rde C, Veloso VG, Cattani VB, Yanavich C, Velasque L, et al. Randomized clinical trial comparing the pharmacokinetics of standard- and increased-dosage lopinavir-ritonavir coformulation tablets in HIV-positive pregnant women. Antimicrob Agents Chemother. 2014;58(5):2884-933. https://doi.org/10.1128/AAC.02599-13.

43. Best BM, Stek AM, Mirochnick M, Hu C, Li H, Burchett SK, et al. Lopinavir tablet pharmacokinetics with an increased dose during pregnancy. J Acquir Immune Defic Syndr. 2010;54(4):381-8.

44. Fayet-Mello A, Buclin T, Guignard N, Cruchon S, Cavassini M, Grawe C, et al. Free and total plasma levels of lopinavir during pregnancy, at delivery and postpartum: implications for dosage adjustments in pregnant women. Antivir Ther. 2013;18(2):17182. https://doi.org/10.3851/IMP2328.

45. Calza L, Manfredi R, Trapani F, Salvadori C, Colangeli V, Borderi $\mathrm{M}$, et al. Lopinavir/ritonavir trough concentrations with the tablet formulation in HIV-1-infected women during the third trimester of pregnancy. Scand J Infect Dis. 2012;44(5):381-7. https://doi.org/10.3109/00365548.2011.642306.

46. Patterson KB, Dumond JB, Prince HA, Jenkins AJ, Scarsi KK, Wang $\mathrm{R}$, et al. Protein binding of lopinavir and ritonavir during 4 phases of pregnancy: implications for treatment guidelines. J Acquir Immune Defic Syndr. 2013;63(1):51-8. https://doi. org/10.1097/QAI.0b013e31827fd47e.

47. Sha BE, Tierney C, Sun X, Stek A, Cohn SE, Coombs RW, et al. Pharmacokinetic exposure and virologic response in HIV-1 infected pregnant women treated with lopinavir/ritonavir: AIDS Clinical Trials Group Protocol A5153S: a substudy to A5150. Jacobs J AIDS HIV. 2015;1(1):003.

48. Stek AM, Mirochnick M, Capparelli E, Best BM, Hu C, Burchett SK, et al. Reduced lopinavir exposure during pregnancy. AIDS. 2006;20(15):1931-9.

49. Mirochnick M, Best BM, Stek AM, Capparelli E, Hu C, Burchett SK, et al. Lopinavir exposure with an increased dose during pregnancy. J Acquir Immune Defic Syndr. 2008;49(5):485-91.

50. Martinez-Rebollar M, Lonca M, Perez I, Soy D, Brunet M, Martin R, et al. Pharmacokinetic study of saquinavir $500 \mathrm{mg}$ plus ritonavir (1000/100 mg twice a day) in HIV-positive pregnant women. Ther Drug Monit. 2011;33(6):772-7. https://doi. org/10.1097/FTD.0b013e318236376d.

51. von Hentig N, Nisius G, Lennemann T, Khaykin P, Stephan C, Babacan E, et al. Pharmacokinetics, safety and efficacy of saquinavir/ ritonavir 1,000/100 mg twice daily as HIV type-1 therapy and transmission prophylaxis in pregnancy. Antivir Ther. 2008;13(8):1039-46.

52. van der Lugt J, Colbers A, Molto J, Hawkins D, Van Der Ende M, Vogel M, et al. The pharmacokinetics, safety and efficacy of boosted saquinavir tablets in HIV type-1-infected pregnant women. Antivir Ther. 2009;14(3):443-50.

53. Eke AC, Brooks KM, Gebreyohannes RD, Sheffield JS, Dooley KE, Mirochnick M. Tenofovir alafenamide use in pregnant and lactating women living with HIV. Expert Opin Drug Metab Toxicol. 2020;16(4):333-42. https://doi.org/10.1080/17425 255.2020.1738384.

54. Xu L, Desai MC. Pharmacokinetic enhancers for HIV drugs. Curr Opin Invest Drugs. 2009;10(8):775-86.

55. Vermeir M, Lachau-Durand S, Mannens G, Cuyckens F, van Hoof B, Raoof A. Absorption, metabolism, and excretion of darunavir, a new protease inhibitor, administered alone and with low-dose ritonavir in healthy subjects. Drug Metab Dispos. 2009;37(4):809-20. https://doi.org/10.1124/dmd.108.024109.

56. Hill A, van der Lugt J, Sawyer W, Boffito M. How much ritonavir is needed to boost protease inhibitors? Systematic review of 17 dose-ranging pharmacokinetic trials. AIDS. 2009;23(17):2237-45. 
57. Hayashi S, Beckerman K, Homma M, Kosel BW, Aweeka FT. Pharmacokinetics of indinavir in HIV-positive pregnant women. AIDS. 2000;14(8):1061-2.

58. Unadkat JD, Wara DW, Hughes MD, Mathias AA, Holland DT, Paul ME, et al. Pharmacokinetics and safety of indinavir in human immunodeficiency virus-infected pregnant women. Antimicrob Agents Chemother. 2007;51(2):783-6.

59. Kosel BW, Beckerman KP, Hayashi S, Homma M, Aweeka FT. Pharmacokinetics of nelfinavir and indinavir in HIV-1-infected pregnant women. AIDS. 2003;17(8):1195-9. https://doi. org/10.1097/00002030-200305230-00011.

60. Aweeka FT, Hu C, Huang L, Best BM, Stek A, Lizak P, et al. Alteration in cytochrome P450 3A4 activity as measured by a urine cortisol assay in HIV-1-infected pregnant women and relationship to antiretroviral pharmacokinetics. HIV Med. 2015;16(3):176-83. https://doi.org/10.1111/hiv.12195.

61. Marzolini C, Gibbons S, Khoo S, Back D. Cobicistat versus ritonavir boosting and differences in the drug-drug interaction profiles with co-medications. J Antimicrob Chemother. 2016;71(7):1755-8. https://doi.org/10.1093/jac/dkw032.

62. Zorrilla C, Wright R, Osiyemi O, Yasin S, Baugh B, Brown K, et al. Total and unbound darunavir (DRV) pharmacokinetics (PK) in HIV-1-infected pregnant women [poster 1012]. In: 19th Conference on Retroviruses and Opportunistic Infections (CROI); 5-8 March 2012; Seattle (WA).

63. Estevez JA, Molto J, Tuneu L, Cedeno S, Antonijoan RM, Mangues MA, et al. Ritonavir boosting dose reduction from 100 to $50 \mathrm{mg}$ does not change the atazanavir steady-state exposure in healthy volunteers. J Antimicrob Chemother. 2012;67(8):2013-9. https://doi.org/10.1093/jac/dks152.

64. van der Lugt J, Gorowara M, Avihingsanon A, Burger D, Ananworanich J, Sringam K, et al. Reducing the boosting dose of ritonavir does not affect saquinavir plasma concentrations in HIV-1-infected individuals. AIDS. 2009;23(9):1176-9.

65. FDA. Tybost: clinical pharmacology and biopharmaceutical review(s) 2015. https://www.accessdata.fda.gov/drugsatfda _docs/nda/2014/2030940rig 1Orig2s000ClinPharmR.pdf. Accessed Nov 2019.

66. Molto J, Curran A, Miranda C, Challenger E, Santos JR, Ribera $\mathrm{E}$, et al. Pharmacokinetics of darunavir/cobicistat and etravirine alone and co-administered in HIV-infected patients. J Antimicrob Chemother. 2018;73(3):732-7. https://doi.org/10.1093/jac/dkx45 9.

67. Scholler-Gyure M, Kakuda TN, Sekar V, Woodfall B, de Smedt $\mathrm{G}$, Lefebvre E, et al. Pharmacokinetics of darunavir/ritonavir and TMC125 alone and coadministered in HIV-negative volunteers. Antivir Ther. 2007;12(5):789-96

68. EMA. Prezista; summary of product characteristics 2019. https ://www.ema.europa.eu/en/documents/product-information/prezi sta-epar-product-information_en.pdf. Accessed 18 Nov 2020.

69. Schalkwijk S, Greupink R, Burger D. Free drug concentrations in pregnancy: bound to measure unbound? $\mathrm{Br} \mathrm{J}$ Clin Pharmacol. 2017;83(12):2595-8. https://doi.org/10.1111/bcp.13432.

70. EACS. The European guidelines for the treatment of HIV-positive adults in Europe: version 10.0. 2019. https://www.eacsociety .org/files/2019_guidelines-10.0_final.pdf. Accessed Nov 2019.

71. DHHS. Recommendations for the use of antiretroviral drugs in pregnant women with HIV infection and interventions to reduce perinatal HIV transmission in the United States. 2018. Available from: https://aidsinfo.nih.gov/guidelines/html/3/perinatal/0. [Accessed Nov 2019].

72. Adegbola A, Abutaima R, Olagunju A, Ijarotimi O, Siccardi M, Owen A, et al. Effect of pregnancy on the pharmacokinetic interaction between efavirenz and lumefantrine in HIV-malaria coinfection. Antimicrob Agents Chemother. 2018;62(10):e01252e1318. https://doi.org/10.1128/aac.01252-18.
73. Byakika-Kibwika P, Lamorde M, Mayito J, Nabukeera L, Namakula R, Mayanja-Kizza H, et al. Significant pharmacokinetic interactions between artemether/lumefantrine and efavirenz or nevirapine in HIV-infected Ugandan adults. J Antimicrob Chemother. 2012;67(9):2213-21. https://doi.org/10.1093/jac/dks207.

74. Kloprogge F, Piola P, Dhorda M, Muwanga S, Turyakira E, Apinan S, et al. Population pharmacokinetics of lumefantrine in pregnant and nonpregnant women with uncomplicated Plasmodium falciparum malaria in Uganda. CPT Pharmacomet Syst Pharmacol. 2013;2:e83. https://doi.org/10.1038/psp.2013.59.

75. Tarning J, Kloprogge F, Dhorda M, Jullien V, Nosten F, White NJ, et al. Pharmacokinetic properties of artemether, dihydroartemisinin, lumefantrine, and quinine in pregnant women with uncomplicated plasmodium falciparum malaria in Uganda. Antimicrob Agents Chemother. 2013;57(10):5096-103. https://doi. org/10.1128/aac.00683-13.

76. McGready R, Stepniewska K, Lindegardh N, Ashley EA, La Y, Singhasivanon $\mathrm{P}$, et al. The pharmacokinetics of artemether and lumefantrine in pregnant women with uncomplicated falciparum malaria. Eur J Clin Pharmacol. 2006;62(12):1021-31. https://doi. org/10.1007/s00228-006-0199-7.

77. Mosha D, Guidi M, Mwingira F, Abdulla S, Mercier T, Decosterd LA, et al. Population pharmacokinetics and clinical response for artemether-lumefantrine in pregnant and nonpregnant women with uncomplicated Plasmodium falciparum malaria in Tanzania. Antimicrob Agents Chemother. 2014;58(8):4583-92. https ://doi.org/10.1128/aac.02595-14.

78. Kreitchmann R, Schalkwijk S, Best B, Wang J, Colbers A, Stek A, et al. Efavirenz pharmacokinetics during pregnancy and infant washout. Antivir Ther. 2019;24(2):95-103. https://doi. org/10.3851/imp3283.

79. Cressey TR, Stek A, Capparelli E, Bowonwatanuwong C, Prommas S, Sirivatanapa P, et al. Efavirenz pharmacokinetics during the third trimester of pregnancy and postpartum. J Acquir Immune Defic Syndr. 2012;59(3):245-52. https://doi. org/10.1097/QAI.0b013e31823ff052.

80. Lamorde M, Wang X, Neary M, Bisdomini E, Nakalema S, Byakika-Kibwika P, et al. Pharmacokinetics, pharmacodynamics, and pharmacogenetics of efavirenz $400 \mathrm{mg}$ once daily during pregnancy and post-partum. Clin Infect Dis. 2018;67(5):785-90. https://doi.org/10.1093/cid/ciy161.

81. Hariparsad N, Nallani SC, Sane RS, Buckley DJ, Buckley AR, Desai PB. Induction of CYP3A4 by efavirenz in primary human hepatocytes: comparison with rifampin and phenobarbital. J Clin Pharmacol. 2004;44(11):1273-81.

82. Maganda BA, Minzi OM, Ngaimisi E, Kamuhabwa AA, Aklillu E. CYP2B $6 * 6$ genotype and high efavirenz plasma concentration but not nevirapine are associated with low lumefantrine plasma exposure and poor treatment response in HIV-malaria-coinfected patients. Pharmacogenomics J. 2016;16(1):88-95. https://doi. org/10.1038/tpj.2015.37.

83. Dooley KE, Denti P, Martinson N, Cohn S, Mashabela F, Hoffmann J, et al. Pharmacokinetics of efavirenz and treatment of HIV-1 among pregnant women with and without tuberculosis coinfection. J Infect Dis. 2015;211(2):197-205. https://doi. org/10.1093/infdis/jiu429.

84. Lopez-Cortes LF, Ruiz-Valderas R, Viciana P, Alarcon-Gonzalez A, Gomez-Mateos J, Leon-Jimenez E, et al. Pharmacokinetic interactions between efavirenz and rifampicin in HIV-infected patients with tuberculosis. Clin Pharmacokinet. 2002;41(9):681-90.

85. Ngaimisi E, Mugusi S, Minzi O, Sasi P, Riedel KD, Suda A, et al. Effect of rifampicin and CYP2B6 genotype on long-term efavirenz autoinduction and plasma exposure in HIV patients with or without tuberculosis. Clin Pharmacol Ther. 2011;90(3):40613. https://doi.org/10.1038/clpt.2011.129. 
86. Denti P, Martinson N, Cohn S, Mashabela F, Hoffmann J, Msandiwa $\mathrm{R}$, et al. Population pharmacokinetics of rifampin in pregnant women with tuberculosis and HIV coinfection in Soweto. South Africa Antimicrob Agents Chemother. 2015;60(3):1234-41. https://doi.org/10.1128/aac.02051-15.

87. Reznicek J, Ceckova M, Tupova L, Staud F. Etravirine inhibits ABCG2 drug transporter and affects transplacental passage of tenofovir disoproxil fumarate. Placenta. 2016;47:124-9. https:// doi.org/10.1016/j.placenta.2016.09.019.

88. Gulati A, Gerk PM. Role of placental ATP-binding cassette (ABC) transporters in antiretroviral therapy during pregnancy. J Pharm Sci. 2009;98(7):2317-35. https://doi.org/10.1002/ jps. 21623 .

89. EMA. Descovy: summary of product characteristics. 2016. https://www.ema.europa.eu/docs/en_GB/document_library/ EPAR_-_Product_Information/human/004094/WC50020765 0.pdf. Accessed 2 Dec 2019.

90. Momper JD, Best B, Wang J, Stek A, Cressey T, Burchett S, et al. Tenofovir alafenamide pharmacokinetics with and without cobicistat in pregnancy [oral presenation THAB0302]. In: 22nd International AIDS Conference; 23-37 July 2018; Amsterdam.

91. Brooks K, Pinilla J, Shapiro D, Capparelli E, Stek A, Mirochnick $\mathrm{M}$, et al. Pharmacokinetics of tenofovir alafenamide $25 \mathrm{mg}$ with PK boosters during pregnancy and postpartum [abstract no. 12]. In: 20th International Workshop on Clinical Pharmacology of HIV, Hepatitis, and Other Antiviral Drugs; 14-16 May 2019; Noordwijk.

92. Eke AC, Mirochnick M. Ritonavir and cobicistat as pharmacokinetic enhancers in pregnant women. Expert Opin Drug Metab Toxicol. 2019;15(7):523-5. https://doi.org/10.1080/17425 255.2019.1628947.

93. Begley R, Das M, Zhong L, Ling J, Kearney BP, Custodio JM. Pharmacokinetics of tenofovir alafenamide when coadministered with other HIV antiretrovirals. J Acquir Immune Defic Syndr. 2018;78(4):465-72. https://doi.org/10.1097/qai.0000000000 001699.

94. Taburet AM, Piketty C, Chazallon C, Vincent I, Gerard L, Calvez $\mathrm{V}$, et al. Interactions between atazanavir-ritonavir and tenofovir in heavily pretreated human immunodeficiency virus-infected patients. Antimicrob Agents Chemother. 2004;48(6):2091-6.

95. EMA. Viread: summary of product characteristics. 2014. Available from: https://www.ema.europa.eu/docs/en_GB/document library/EPAR_-_Product_Information/human/000419/WC500 051737.pdf. [Accessed Dec 2019].

96. EMA. Reyataz: summary of product characteristics. 2016. https://www.ema.europa.eu/docs/nl_NL/document_library/ EPAR_-_Product_Information/human/000494/WC50005638 0.pdf. Accessed Dec 2019.

97. von Hentig N, Dauer B, Haberl A, Klauke S, Lutz T, Staszewski $\mathrm{S}$, et al. Tenofovir comedication does not impair the steady-state pharmacokinetics of ritonavir-boosted atazanavir in HIV-1-infected adults. Eur J Clin Pharmacol. 2007;63(10):935-40. https ://doi.org/10.1007/s00228-007-0344-y.

98. Best BM, Burchett S, Li H, Stek A, Hu C, Wang J, et al. Pharmacokinetics of tenofovir during pregnancy and postpartum. HIV Med. 2015;16(8):502-11. https://doi.org/10.1111/hiv.12252.

99. Colbers AP, Hawkins DA, Gingelmaier A, Kabeya K, Rockstroh $\mathrm{JK}$, Wyen C, et al. The pharmacokinetics, safety and efficacy of tenofovir and emtricitabine in HIV-1-infected pregnant women. AIDS. 2013;27(5):739-48. https://doi.org/10.1097/QAD.0b013 e32835c208b.

100. Bertz RJ, Persson A, Chung E, Zhu L, Zhang J, McGrath D, et al. Pharmacokinetics and pharmacodynamics of atazanavircontaining antiretroviral regimens, with or without ritonavir, in patients who are HIV-positive and treatment-naive. Pharmacotherapy. 2013;33(3):284-94. https://doi.org/10.1002/phar.1205.
101. Gonzalez-Requena D, Bonora S, Cavechia I, Veronese L, Di Garbo A, Canta F, et al. Atazanavir Ctrough is associated with efficacy and safety at 24 weeks: definition of therapeutic range [abstract no. 60]. In: 6th International Workshop on Clinical Pharmacology of HIV Therapy; 28-30 April 2005; Quebec (QC).

102. Haaland RE, Otieno K, Martin A, Katana A, Dinh C, Slutsker L, et al. Short communication: reduced nevirapine concentrations among HIV-positive women receiving mefloquine for intermittent preventive treatment for malaria control during pregnancy. AIDS Res Hum Retrovir. 2018;34(11):912-5. https ://doi.org/10.1089/aid.2018.0042.

103. Lupattelli A, Spigset O, Twigg MJ, Zagorodnikova K, Mardby AC, Moretti ME, et al. Medication use in pregnancy: a cross-sectional, multinational web-based study. BMJ Open. 2014;4(2):e004365. https://doi.org/10.1136/bmjopen-2013004365 .

104. Headley J, Northstone K, Simmons H, Golding J. Medication use during pregnancy: data from the Avon Longitudinal Study of Parents and Children. Eur J Clin Pharmacol. 2004;60(5):355-61. https://doi.org/10.1007/s00228-004-0775-7.

105. Griessinger JA, Hauptstein S, Laffleur F, Netsomboon K, Bernkop-Schnurch A. Evaluation of the impact of multivalent metal ions on the permeation behavior of dolutegravir sodium. Drug Develop Indust Pharm. 2016;42(7):1118-26. https://doi. org/10.3109/03639045.2015.1115869.

106. Patel P, Song I, Borland J, Patel A, Lou Y, Chen S, et al. Pharmacokinetics of the HIV integrase inhibitor S/GSK1349572 co-administered with acid-reducing agents and multivitamins in healthy volunteers. J Antimicrob Chemother. 2011;66(7):156772. https://doi.org/10.1093/jac/dkr139.

107. Krishna R, East L, Larson P, Valiathan C, Butterfield K, Teng Y, et al. Effect of metal-cation antacids on the pharmacokinetics of 1200 mg raltegravir. J Pharm Pharmacol. 2016;68(11):1359-65. https://doi.org/10.1111/jphp.12632.

108. Kiser JJ, Bumpass JB, Meditz AL, Anderson PL, Bushman $\mathrm{L}$, Ray M, et al. Effect of antacids on the pharmacokinetics of raltegravir in human immunodeficiency virus-seronegative volunteers. Antimicrob Agents Chemother. 2010;54(12):4999-5003.

109. Moss DM, Siccardi M, Murphy M, Piperakis MM, Khoo SH, Back DJ, et al. Divalent metals and $\mathrm{pH}$ alter raltegravir disposition in vitro. Antimicrob Agents Chemother. 2012;56(6):3020-6. https://doi.org/10.1128/AAC.06407-11.

110. Roberts JL, Kiser JJ, Hindman JT, Meditz AL. Virologic failure with a raltegravir-containing antiretroviral regimen and concomitant calcium administration. Pharmacotherapy. 2011;31(10):298e-302e.

111. Mulligan N, Best BM, Wang J, Capparelli EV, Stek A, Barr E, et al. Dolutegravir pharmacokinetics in pregnant and postpartum women living with HIV. AIDS. 2018;32(6):729-37. https://doi. org/10.1097/QAD.0000000000001755.

112. Watts DH, Stek A, Best BM, Wang J, Capparelli EV, Cressey TR, et al. Raltegravir pharmacokinetics during pregnancy. J Acquir Immune Defic Syndr. 2014;67(4):375-81. https://doi. org/10.1097/QAI.0000000000000318.

113. Blonk MI, Colbers AP, Hidalgo-Tenorio C, Kabeya K, Weizsacker K, Haberl AE, et al. Raltegravir in HIV-1-infected pregnant women: pharmacokinetics, safety, and efficacy. Clin Infect Dis. 2015;61(5):809-16. https://doi.org/10.1093/cid/civ366.

114. Farthing $\mathrm{C}$, Khanlou H. Coadministration of atazanavir with proton-pump inhibitors and H2-blockers [abstract no. P289.2004]. In: 7th International Congress on Drug Therapy in HIV Infection; November 2004; Glasgow.

115. Schalkwijk S, Colbers A, Konopnicki D, Gingelmaier A, Lambert J, van der Ende M, et al. Lowered rilpivirine exposure during third trimester of pregnancy in HIV-1-positive women. Clin 
Infect Dis. 2017;65(8):1335-411. https://doi.org/10.1093/cid/ cix534.

116. Tran AH, Best BM, Stek A, Wang J, Capparelli EV, Burchett SK, et al. Pharmacokinetics of rilpivirine in HIV-infected pregnant women. J Acquir Immune Defic Syndr. 2016;72(3):289-96. https ://doi.org/10.1097/QAI.0000000000000968.

117. Osiyemi O, Yasin S, Zorrilla C, Bicer C, Hillewaert V, Brown $\mathrm{K}$, et al. Pharmacokinetics, antiviral activity, and safety of Rilpivirine in pregnant women with HIV-1 infection: results of a phase $3 \mathrm{~b}$, multicenter, open-label study. Infect Dis Ther. 2018;7(1):147-59. https://doi.org/10.1007/s40121-017-0184-8.

118. World Health Organization. Updated recommendations on firstline and second-line antiretroviral regimens and post-exposure prophylaxis and recommendations on early infant diagnosis of HIV: interim guidance. 2018. https://www.who.int/hiv/pub/guide lines/ARV2018update/en/. Accessed 27 Aug 2018.

119. Dooley KE, Sayre P, Borland J, Purdy E, Chen S, Song I, et al. Safety, tolerability, and pharmacokinetics of the HIV integrase inhibitor dolutegravir given twice daily with rifampin or once daily with rifabutin: results of a phase 1 study among healthy subjects. J Acquir Immune Defic Syndr. 2013;62(1):21-7. https ://doi.org/10.1097/QAI.0b013e318276cda9.

120. Bollen P, Freriksen J, Konopnicki D, Weizsacker K, Hidalgo Tenorio C, Molto J, et al. The effect of pregnancy on the pharmacokinetics of total and unbound dolutegravir and its main metabolite in women living with human immunodeficiency virus. Clin Infect Dis. 2020. https://doi.org/10.1093/cid/ciaa006.

121. Waitt C, Orrell C, Walimbwa S, Singh Y, Kintu K, Simmons B, et al. Safety and pharmacokinetics of dolutegravir in pregnant mothers with HIV infection and their neonates: a randomised trial (DolPHIN-1 study). PLoS Med. 2019;16(9):e1002895. https ://doi.org/10.1371/journal.pmed.1002895.

122. Fischer JH, Sarto GE, Hardman J, Endres L, Jenkins TM, Kilpatrick SJ, et al. Influence of gestational age and body weight on the pharmacokinetics of labetalol in pregnancy. Clin Pharmacokinet. 2014;53(4):373-83. https://doi.org/10.1007/s40262-013-0123-0.

123. Jeong H, Choi S, Song JW, Chen H, Fischer JH. Regulation of UDP-glucuronosyltransferase (UGT) $1 \mathrm{~A} 1$ by progesterone and its impact on labetalol elimination. Xenobiotica. 2008;38(1):62-75. https://doi.org/10.1080/00498250701744633.

124. Dallmann A, Pfister M, van den Anker J, Eissing T. Physiologically based pharmacokinetic modeling in pregnancy: a systematic review of published models. Clin Pharmacol Ther. 2018;104(6):1110-24. https://doi.org/10.1002/cpt.1084.

125. Codaccioni M, Bois F, Brochot C. Placental transfer of xenobiotics in pregnancy physiologically-based pharmacokinetic models: structure and data. Comput Toxicol. 2019;12:100111. https://doi. org/10.1016/j.comtox.2019.100111. 